\title{
Türkiye'de Ulusal ve Bölgesel Politika Belgelerinde Sürdürülebilir Turizm Planlaması
}

\begin{abstract}
Sustainable tourism planning in national and regional policy documents in Turkey
\end{abstract}

Volkan İdris Sarı*a

\begin{tabular}{|c|c|}
\hline \multicolumn{2}{|c|}{ Makale Bilgisi } \\
\hline $\begin{array}{l}\text { DOI: } \\
10.3368\end{array}$ & aucbd.615191 \\
\hline $\begin{array}{l}\text { Makale } \\
\text { Geliş: } \\
\text { Kabul: }\end{array}$ & $\begin{array}{l}\text { eçmişi: } \\
04.09 .2019 \\
01.11 .2019 \\
\end{array}$ \\
\hline $\begin{array}{l}\text { Anahtaı } \\
\text { Sürdürü } \\
\text { Turizm } \\
\text { Planlam } \\
\text { Bölgese } \\
\text { Turizm }\end{array}$ & $\begin{array}{l}\text { elimeler: } \\
\text { bilir Kalkınma } \\
\text { Gelişme } \\
\text { ratejisi }\end{array}$ \\
\hline
\end{tabular}

\begin{tabular}{l} 
Article Info \\
\hline DOI: \\
10.33688/aucbd.615191 \\
\hline Article History: \\
Received: 04.09.2019 \\
Accepted: 01.11 .2019 \\
\hline Keywords: \\
Sustainable Development \\
Tourism \\
Planning \\
Regional Development \\
Tourism Strategy
\end{tabular}

\footnotetext{
*Sorumlu Yazar/Corresponding Author: Volkan İdris Sarı, volkan.i.sari@gmail.com

a Ankara Üniversitesi, Sosyal Bilimler Enstitüsü, Ankara, Türkiye, http://orcid.org/0000-0001-7032-8069
}

\begin{abstract}
$\ddot{O} z$
Bu çallşmanın amacı Türkiye'de ulusal ve bölgesel politika belgelerinde sürdürülebilir turizm planlamasınin yeri ve öneminin incelenmesidir. Değişen ve dönüşen planlama yaklaşımlarına uygun olarak turizm planlaması da katılımcı, stratejik ve sürdürülebilir bir nitelik kazanmıştır. Paydaş analizleri, kamu-özel işbirlikleri, taşıma kapasitesi hesaplart ve izleme ve değerlendirme araçları ile sürdürülebilir turizm planlaması yenilikçi bir yaklaşım olarak ortaya çıkmıştır. Bu çalışma ile sürdürülebilir turizm planlamasına yönelik yaşanan dönüşüm ele alınmakta ve ülkemizde bu planlama yaklaşımına dönük mevcut durumu politika belgeleri üzerinden incelenmektedir. Bu incelemede turizm politikalarını belirleyen temel belgelere yönelik içerik analizi yöntemi uygulanmıştır. Bu çerçevede incelenen dokümanlarda "sürdürülebilir turizm planlaması" ve onun temel unsurlarına yer verilme sıklĭg ve derinliği tematik içerik analizi yöntemi ile değerlendirilmiştir.
\end{abstract}

\begin{abstract}
The aim of this study is to examine the role and importance of sustainable tourism planning at national and regional policy documents in Turkey. In accordance with changing and transforming planning approaches, tourism planning has gained a participatory, strategic and sustainable nature. Sustainable tourism planning has emerged as an innovative approach through stakeholder analyzes, public-private partnerships, transport capacity calculations and monitoring and evaluation tools. With this study, transformation of sustainable tourism planning is discussed and current situation of this planning approach in our country is examined through policy documents. In this study, content analysis method was applied for the basic documents determining tourism policies. Within the framework of these documents, the frequency and depth of "sustainable tourism planning" method.
\end{abstract}




\section{Giriş}

Sürekli artan (teşvik edilen) insan ihtiyaçlarının karşılanabilmesi için doğal kaynakların hızlı tüketilmesi daha önce sınırsız olduğu varsayılan birçok kaynağın azalmasıyla sonuçlanmıştır (Meadows vd., 1972). Bu durum 1970'lerden sonra yaygın olarak kullanılmaya başlanan sürdürülebilirlik kavramının günümüzde oldukça popüler hale gelmesine neden olmuştur (Jacobus, 2006:92). Bu kavram temel olarak nesiller arası adalet vurgusu ile ortaya çıkmış (Tekeli, 2013:6) ve zaman içerisinde toplumsal kalkınma, sosyal adalet, kapsayıcı büyüme, katılımcı yönetişim gibi kavramları da içine alarak genişlemiş hatta sürekli içeriği yeniden ele alınan bir ahlak kuralı ya da ilkesi olarak tanımlanmıştır (Tekeli, 2001:730). Günümüzde "sürdürülebilir" kelimesi, önüne geldiği kavramın çevreye duyarlı, insan odaklı, adil ve katılımcı bir şekilde ele alınacağını anlatmaya başlamıştır.

Her ne kadar turizm, kullandığı kaynakları yok edebilme potansiyeline sahip olsa da sürdürülebilirlik kavramı ile çok geç tanışmıştır. Turizmin bir ekonomik sektör olarak ortaya çıkması, giderek daha fazla büyümesi ve bu büyümenin artarak devam edeceğine yönelik tahminlerin yapılması zaman içerisinde sosyal, kültürel ve çevresel etkilerinin daha fazla dikkat çekmesine neden olmuştur. Zira turizm arzı arttıkça kullandığı ve tükettiği kaynaklar da katlanarak artmaktadır. Diğer yandan küresel ölçekte sürdürülebilirlik gündeminin önem kazanması ile birlikte bunun bir yansıması olarak "sürdürülebilir turizm" gündemi yaygınlaşmaya başlamıştır. Kitle turizminin yeni destinasyonlar keşfederek gösterdiği ciddi artışa paralel olarak sürdürülebilir turizm literatürü de aynı hızla gelişmiştir.

Sürdürülebilir turizm kavramı, ilk önce sürdürülebilir kalkınma kavramıyla yakından bağlantılı olarak ortaya çıkmıştır (Torres-Delgado ve Palomeque, 2014:124). Sürdürülebilir turizm; turizmin hem ekonomik hem de toplumsal katkılarının sürdürülebilir biçimde büyümesi ve çevrenin ve doğal kaynakların yine sürdürülebilir biçimde kullanılmasını gerektirir (Liu, 2003:462). Dünya Turizm Örgütü (DTÖ) sürdürülebilir turizmi; "turistlerin, sektörün, çevrenin ve ev sahibi toplulukların ihtiyaçlarını karşılarken, bugünkü ve gelecekteki ekonomik, sosyal ve çevresel etkileri tam olarak dikkate alan turizm" olarak tanımlamaktadır (UNWTO, 2017). Bu tanıma bağlı olarak; ekolojik ayak izi tekniği, net birincil verimlilik muhasebesi, enerji muhasebesi, taşıma kapasitesinin ayarlaması ve yaşam-döngüsü analizi sürdürülebilir turizmin en sık baş vurulan araçları olmuştur (Sonuç, 2014:26).

$\mathrm{Bu}$ arz yönlü yaklaşımın yanında sürdürülebilir turizm, artık talep yönüyle de karşımıza çıkmaktadır. Dünya turizminde değişen ve dönüşen ziyaretçi eğilimleri dikkate alındığında, sağlıklı ve sürdürülebilir yaşam biçimi ilkesini benimsemiş tüketicilerin sayısı her geçen gün artmaktadır. $\mathrm{Bu}$ ziyaretçilerin seyahat edecekleri yerdeki çevresel duyarlılığa daha fazla önem vermeye başladıkları ve buna bağlı olarak turizm sektöründeki paydaşların çevre duyarlılığı ve sürdürülebilir turizm odaklı faaliyetlere ağırlık vermeye çalıştıkları gözlemlenmektedir (Kültür ve Turizm Bakanlığı, 2018:41). Çevre duyarlılığını ve ekolojik sürdürülebilirliği dikkate alan kullanıcılara yönelik Yeşil Anahtar, EU Eco-Label, Green Globe gibi geliştirilen programlara dahil olan, enerji tüketimini en aza indirecek yöntemleri benimseyen tesislerin sayısı giderek artmaktadır (Kalkınma Bakanlığı, 2014b:25).

Sürdürülebilir turizme ilişkin iki temel algı bulunmaktadır. Bunlardan ilki sürdürülebilir turizmi genel turizm portföyünün doğal ve kültürel çevreye hassas bir şekilde gerçekleştirilen bir türü olarak görmektedir. Diğer bakış açısı ise tüm turizm türlerini kapsayan ve turizmin dikkate alması gereken çevresel, ekonomik ve sosyal unsurları içeren bir üst hedeftir. Her ne kadar firma bazında bazı uygulamalar, ilk yaklaşımı ifade etmeye devam etse de bu çalışmada ve genel olarak literatürde, ikinci yaklaşım esas alınmaktadır. Bu nedenle Birleşmiş Milletler Çevre Programı (BMÇP) ve DTÖ tarafından 
birlikte hazırlanan Turizmi Daha Sürdürülebilir Kılma Raporu "ayrı veya özel bir turizm biçimi değil aksine, her türlü turizm faaliyetini daha sürdürülebilir kılmaya çalışmalıdır (UNEP ve UNWTO, 2005:2)" ifadesiyle açılmaktadır. İkinci yaklaşımın karşılaştığı en temel sorun ise insanlığın refahını sağlama ve genel toplumsal kalkınmaya katkı verme gibi büyük idealleri gerçekleştirmede yaşanan zorluklardır. Buna bir de sürdürülebilirlik gündeminde değinilen ve küresel ölçekte artan çevre sorunları eklenince kavram kaldırabileceğinden fazla bir yükü yüklenmiş görünmektedir.

Talebin artmasına bağlı olarak gelişen turizmin kontrolsüz bir biçimde sürdürülmemesi için planlama en önemli araçtır (Özgüç, 2007:182). Bu nedenle sürdürülebilir turizm literatüründe en çok önem verilen konulardan birisi de sürdürülebilir turizmin planlanması olmuştur. Diğer bütün sektörlerde olduğu gibi turizm için de plansız yönetim, içinden çıkılması güç sorunların oluşmasına ve turizme konu olan kaynakların hızlı bir şekilde tükenmesine yol açabilmektedir (Bardakoğlu, 2014:118). Günümüzde giderek daha fazla kaynak kullanma talebi olan turizmin planlaması bir tercihten çok bir zorunluluğa dönüşmüştür. Zira, turizmin planlı olarak geliştiği bölgeler, turizmin kontrolsüz olarak geliştiği yerlere göre daha yüksek rekabet gücüne sahip olmuştur (Bardakoğlu, 2014:118). Özellikle kalkınmakta olan ülkelerde turizm sektöründen yeterince faydalanabilmek için ulusal, bölgesel, yerel ve destinasyon düzeylerinde planlama çalışmalarına ve bunlar arasında tamamlayıcılık ve koordinasyonun sağlanmasına gerek duyulmaktadır. Nitekim bir ülkede planlama mekanizması iyi çalışmıyor veya turizmin gelişmesine yönelik izinler plansız bir şekilde veriliyor ise turizm, sürdürülebilir kalkınma için gerekli olan özel niteliklere zarar verebilir. Diğer bir ifadeyle, plansız bir arz ile bindiği dalı kesebilir. Sürdürülebilir turizmin koruma, yenilenme ve ekonomik kalkınmayı teşvik edebileceği ve destekleyebileceği ve aynı zamanda ziyaretçiler ile ev sahibi toplulukların yaşam kalitesini yükseltmesine yardımcı olabileceği kabul edilmektedir (Connell vd., 2009:868). Sürdürülebilir turizm planlamasının en temel argümanı planlı turizm gelişmesi ile meydana gelecek sosyo-ekonomik faydanın yerel halkın sürece katılması ile çevreye yayılacağıdır (Bardakoğlu, 2014:126).

Ülkemizde de turizmin kaynak değerlerine zarar verme, hatta yok etme potansiyeli anlaşıldıkça, sürdürülebilir turizm gündemi biraz gecikmeli de olsa dikkate alınmaya başlamıştır. Özellikle 1980 sonrası süreçte kitle turizminin hakim turizm karakteri haline gelmesi ve bunun kamu politikaları ile teşvik edilmesi turizmin mekânsal olarak çok dar bir alanda kaynak değerleri tehdit eder bir şekilde yığınlaşmasına neden olmuştur. Gelinen aşamada, bunun sürdürülebilir olmadığı anlaşılmış ve temel politika dokümanları ile bu sürecin dengelenmesi yönünde öncelikler belirlenmeye başlamıştır. $\mathrm{Bu}$ çalışmada turizme ilişkin temel politika dokümanlarında söz konusu önceliklere yer verilme düzeyi incelenerek sürdürülebilir turizm ve sürdürülebilir turizm planlamasının politika düzeyinde ulaştığı seviye değerlendirilmiştir.

\section{Yöntem}

Çalışmada temel olarak veri analizi, literatür taraması ve doküman analizi teknikleri kullanılmış, ilk olarak ülkemizdeki turizm gelişim süreci kısaca açıklandıktan sonra, ulusal düzeyde seçilen göstergeler itibarıyla sürdürülebilir turizme duyulan ihtiyaç ortaya konulmuştur. Turizm sektörünün ülkemizdeki mevcut durumu ve gelişimi incelenirken Türkiye İstatistik Kurumu (TÜİK), Türkiye Seyahat Acenteleri Birliği (TÜRSAB) ve ilgili bakanlıklar tarafindan üretilen veriler analiz edilerek turizmin gelişiminin ana karakteri ortaya konulmaya çalışılmıştır.

Türkiye'deki temel ulusal, bölgesel ve sektörel politika dokümanları, sürdürülebilir turizm ve sürdürülebilir turizm planlaması bakımından değerlendirilmiştir. Bu kapsamda turizm politikalarını 
belirleyen temel belgelere yönelik doküman analizi yöntemi kullanılmıştır. Bu kapsamda kalkınma planları, Türkiye Turizm Stratejisi ve Eylem Planı (TTS), III. Turizm Şurası Raporları, sürdürülebilir kalkınmaya ilişkin ulusal dokümanlar, Bölgesel Gelişme Ulusal Stratejisi (BGUS) ve 26 Düzey 2 bölgesi itibarıyla hazırlanan bölge planları irdelenmiştir.

Doküman analizi, araştırma konusu ile ilgili kavram ve materyallerin çözümlenmesi işlemidir (Gürbüz ve Şahin, 2014:182). Bu çerçevede incelenen dokümanlarda "sürdürülebilir turizm planlaması" ve ilişkili kavramlara yer verilme sıklığı ve derinliği tematik içerik analizi yöntemi ile değerlendirilmiştir. Tematik içerik analizi (meta sentez), belli bir alanı konu edinen dokümanların nitel bir anlayışla ele alınıp, benzerlik ve farklılıkların karşılaştırmalı olarak incelenmesidir. İçerik analizlerinde incelemeye alınan doküman sayısının az olduğu durumlarda bu yöntemin tercih edilmesi önerilmektedir (Çalık ve Sözbilir, 2014:34).

İçerik analizinde sadece "sürdürülebilir turizm" kavramı değil BMÇP ve DTÖ tarafından sürdürülebilir turizm için belirlenen 12 temel ilkeye (ekonomik süreklilik, yerel refah, ziyaretçi memnuniyeti, sosyal eşitlik, istihdam kalitesi, yerel kontrol, kültürel zenginlik, fiziki bütünlük, biyolojik çeşitlilik, toplumsal refah, kaynak verimliliği ve çevresel saflık) yapılan atıflar da dikkate alınmıştır (UNEP ve UNWTO, 2005). Bu kriterler bir yandan politika yapıcılar için yol gösterici nitelikte olup, diğer yandan araştırmacılar için önemli bir analiz çerçevesi ortaya koymaktadır (Somuncu ve Yiğit, 2009).

Ayrıca sürdürülebilir turizm planlamasının dört temel unsuru belirlenmiş ve incelenen dokümanlarda bu unsurların ele alınma düzeyleri analiz edilmiştir. İlk unsur turizm faaliyetlerinden doğrudan ya da dolaylı olarak etkilenen tüm ilgili paydaşların planlama sürecine katılımı ile ilgilidir. Çünkü sürdürülebilir turizm planlamasının başarısı sadece plancıların yürüttüğü bir sürecin ötesinde sektörün tüm kesimlerinin tüm planlama sürecine katılması ile mümkün olabilecektir (UNWTO, 2013:19-20). Stratejik planlama ikinci unsur olarak ele alınmıştır. Sürdürülebilir turizm planlamasında uzun vadeli bir yön (vizyon) oluşturan, kaynakların tahsisi ve izlenmesi için hedefler ve stratejiler ile ayrıntılı eylem programları ortaya koyan ve sistem ve çevresi arasında optimal bir uyum sağlayan stratejik planlama yaklaşımı zaruridir (Ruhanen, 2006:3). Üçüncü unsur, bir destinasyonun kabul edebileceği/kaldırılabileceği azami turist sayısı hesaplanmasına dayanan taşıma kapasitesidir. Sürdürülebilir turizm yaklaşımında taşıma kapasitesi hesapları salt fiziksel altyapı üzerindeki etkiler gözetilerek değil aynı zamanda sosyal, kültürel ve ekonomik etkiler de dikkate alınarak yapılmalıdır. $\mathrm{Bu}$ kapsamda taşıma kapasitesi planlamadan uygulamaya tüm süreçte bir eşik değer olarak kabul edilmeli ve sürdürülebilir turizm planlaması tamamlanmadan bu eşik değerin geçilmemesine özen gösterilmelidir (Bardakoğlu, 2014:127). Son unsur ise kendine özgü hedef ve ilkeleri olan sürdürülebilir turizm faaliyetlerinin arz ve talep yönlü izlenmesi ve değerlendirilmesidir. Bu kapsamda, başta korunan alanlar olmak üzere tüm destinasyonlarda ziyaretçilerin çevresel ve sosyal etkileri takip edilmeli ve yönetilmelidir (Eagles vd., 2002:151).

Turizme ilişkin politika dokümanlarının tamamının ele alınamaması ve doküman analizindeki öznel değerlendirmeler çalışmanın sınırlılıklarını oluşturmaktadır. Ayrıca politika belgeleri üzerinden yapılan analizlerle sınırlı tutulan bu çalışmanın devamında sürdürülebilir turizme ilişkin ülkemizdeki örnek uygulamalar incelenebilir, burada incelenen ulusal ve bölgesel politika belgeleri ve planların uygulamaya ne düzeyde yansıdığı araştırılabilir ve bunların başarı ve başarısızlıkları üzerinden 
sürdürülebilir turizmin teoriden uygulamaya, politika düzeyinden proje düzeyine nasıl indirilebileceği tartışılabilir.

\section{Türkiye'de Turizmin Gelişimi ve Sürdürülebilir Turizme Duyulan İhtiyaç}

Türkiye, 46,5 milyon turistle 2018 yılında dünyada en çok turist çeken altıncı ülke olmuştur. Bu turist ziyaretlerinden yaklaşık 30 milyar ABD Doları gelir elde etmiştir. Ekonomik açıdan incelendiğinde turizmin Türkiye ekonomisindeki yeri ve önemi zaman içerisinde katlanarak artmıştır. 1963 yılında turizm gelirlerinin GSMH içindeki payı yüzde 0,1 ve turizm gelirlerinin ihracata oranı yüzde 2,3 düzeyinde idi. 1980'lerle birlikte bu verilerden ilki yüzde 1, ikincisi ise yüzde 10 seviyesine çıkmıştır. 2018 yılında 3,8 olan turizmin GSMH içindeki payı son 10 yılda ortalama yüzde 4 düzeyinde gerçekleşmiştir. İhracata oran ise 2002 yılında yüzde 33,9 düzeyine çıkmış ve son 10 yılda ortalama yüzde 20 olarak hayata geçmiştir (TÜRSAB, 2018). Bu haliyle Türkiye'de turizm, dünyadaki eğilimlere paralel olarak ana sektörler ile rekabet edecek düzeye ulaşan bir sektör haline gelmiştir (Kalkınma Bankası, 1998:32). Ayrıca küresel ölçekte Türkiye'nin karşılaştırmalı rekabet üstünlüğünün bulunduğu bir sektör haline evrilmiştir (Yamanoğlu, 2010:11).

Turizmin gelişimi kalkınma planları üzerinden incelendiğinde ise turizmin zaman içerisinde derinlik kazandığı görülebilmektedir. Kalkınma planları ile turizm sektörünün sürekli olarak büyütülmesi sağlanmış ve ortaya konulan sayısal hedeflere ulaşılmıştır. Diğer bir ifadeyle sektörel plan ve stratejilerin yokluğunda kalkınma planları turizmin gelişmesinde belirleyici olmuştur (Kervankıran, 2015:606). Bu çerçevede başlangıçta devlet eliyle kurulan işletmeler, organizasyon ve kurumsal yapılanma hedefleri öncelikliyken; fiziki planlama, ulaşım ve altyapı gündeme gelmiştir. Arz kapasitesinin geliştirilmesine odaklanan bu yaklaşım yerini son dönemde hizmet kalitesinin artırılması, katılımcılık, tanıtım ve pazarlamaya bırakmıştır (Çatal, 2010:38 aktaran Dadakoğlu, 2016:75). 1982 yılında yasalaşan Turizm Teşvik Kanunu'na kadar olan döneme kadar temel olarak kamu yatırımları ile büyüyen sektör, bu tarihten sonra özel sektör yatırımları ile yönlendirilmiştir (Kalkınma Bakanlığı, 2018a). 1982 sadece yatırımlar açısından değil, aynı zamanda turizm arzı için de bir dönüm noktası olmuştur. Bu tarihten sonra Türk turizminin ana karakteri şekillenmeye başlamıştır. Bu dönemden itibaren Türkiye'de turizm sektörü kitle turizmine odaklanmıştır.

Ucuz, her şey dahil sistemi ile çalışan kitle turizminin dönemsel olarak Haziran-Eylül dönemine ve mekânsal olarak ise İstanbul ile güney ve batı kıyılarındaki birkaç ilçeye sıkıştığını söyleyebiliriz. Türkiye turizminde önemli oranda mevsimlik yoğunlaşma eğilimi bulunmaktadır (Kozak vd., 1997:118). 1990-2016 yılları arasındaki turist konaklamalarının aylar itibarıyla dağılımı incelendiğinde, bazı istisna yılları haricinde turizmin yarısından fazlasının Haziran-Eylül döneminde gerçekleştiğini görülmektedir. Bu ana karakterin neredeyse ülkemizdeki turizm ile özdeşleştiği ve herhangi bir değişim sinyali olmadığı anlaşılmaktadır. Bu da 2000'li yıllardan itibaren gündeme gelen turizmin dört mevsime yayılması hedefinde istenilen başarının sağlanamadığını göstermektedir.

Ülkemizdeki turizmin diğer önemli bir gündem maddesi de turizmin ülke sathına yayılmasıdır. Politika belgelerinde bu husus sürekli dile getirilmiş olsa da hala turizm faaliyetleri çok açık bir şekilde kıyı alanlarına yoğunlaşmıştır (Kozak vd., 1997:120). Turistik tesislerdeki varışlar dikkate alındığında 2016 yılında toplam varışların \%86'sının 5 ilde (Antalya, İstanbul, Muğla, Aydın ve İzmir) gerçekleştiği anlaşılmaktadır.2000-2016 döneminde yaşanan değişim incelendiğinde ise bu oranın yüzde 82-88 arasında değişim gösterdiği görülmektedir. Turizm varışlarında ilk 10 il (Ankara, Antalya, Aydın, Bursa, Çanakkale, Denizli, İstanbul, İzmir, Muğla ve Nevşehir) dikkate alındığında ise bu oran yüzde 93 
düzeyine yükselmektedir. İlçe bazında yapılan hesaplamada ise turizmin yığınlaşması çok daha dikkat çekici bir şekilde ortaya çıkmaktadır. En çok yabancı turist kabul eden ilk beş (Fatih, Manavgat, Alanya, Serik ve Beyoğlu), on ve yirmi ilçe sırasıyla toplam turist varışlarının yüzde 39, 59 ve 78'ini teşkil etmektedir. Yüzölçüm olarak bakıldığında; en çok turist kabul eden beş ilçenin yüzölçümü $5.209 \mathrm{~km}^{2}$ olup, bu alan ülke yüzölçümünün ancak yaklaşık binde 7'sini oluşturmaktadır. İlk on ilçe ele alındığında ise bu oran binde 9'a $\left(6.687 \mathrm{~km}^{2}\right)$ çıkmaktadır.

Bu sonuçlar bize ülke turizminin mekânsal olarak çok küçük bir coğrafi alana sıkıştığını (Kervankıran ve Çuhadar, 2016:62) ve buralarda taşıma kapasitelerinin çok üstüne çıkan kullanımlara neden olduğunu göstermektedir. Özellikle kıyı bölgelerinde yoğunlaşan bu kullanımlar hızlı ve düzensiz yapılaşma, kontrolsüz büyüme sonucu kıyıların doğal yapısının bozulması ve biyolojik çeşitliliğin ve doğal hayatın tahribatı gibi sürdürülebilirlik sorunlarını doğurmaktadır (Kültür ve Turizm Bakanlığ1, 2018:101-102).

Diğer bir husus ise ülke ekonomisinin turizme bağımlılığıdır (Tosun, 2001:299). 1980 sonras1 ithal ikameci yaklaşımdan dışa açık ve ihracata dönük ekonomi politikalarına geçildikten sonra ülkemiz sürekli dış ticaret açığı vermektedir. Ülkemizdeki ihracat artmakla birlikte ithalatın da sürekli artmasıyla yapısal bir açık oluşmuştur. Turizm bu açığın kapatılmasında 1990'lı yıllardan itibaren çok önemli bir rol üstlenmiştir (Tutar ve Tutar, 2004:95). Ekonomik kriz y1llarında (2001, 2009) çok daha yüksek olmak kaydıyla turizm dış ticaret açığının ortalama yaklaşık yarısını karşılama kabiliyetine sahiptir. Oluşan ekonomik bağımlılık sonucunda, olumsuz sosyal ve çevresel etkilere rağmen kamu politikaları ile turizmin sürekli büyütülmesi desteklenmiştir (Çetinel ve Yolal, 2009:46). Makro-ekonomik sorunlar ve ekonominin turizm kaynaklı döviz gelirlerine bağımlılığı, kaynak değerleri tüketen turizmden sürdürülebilir turizme dönüşümü zorlaştırmaktadır (Tosun, 2001:299).

$\mathrm{Bu}$ veriler ortalama turist harcamalarının düşüklügü ile birlikte değerlendirildiğinde turizm gelirlerinin artırılması daha fazla turist çekme yaklaşımını doğurmaktadır. Yaklaşık 1.100 ABD Doları olan dünya ortalaması ile karşılaştırıldığında, Türkiye 2018 yılında kişi başı yaklaşık 650 ABD Doları turist harcaması ile hala "ucuz ülke" kategorisinde yer almaktadır. Bunun nedeni turizm arzında doğal kaynakların aşırı kullanımına odaklı kitle turizminin ve her şey dahil sisteminin ön plana çıkması, çeşitli politikalar ile bu turizm türünün desteklenmeye devam edilmesidir. Turizm pazarının çeşitlendirilmemesi, alternatif turizm türlerinin yeterince desteklenmemesi ve turizme ilişkin makro planların yapılamaması bu sorunun kalıcı hale gelmesine neden olmuştur.

Türkiye'deki turizmin gelişme süreci bu çalışmada kullanılan göstergeler bağlamında değerlendirildiğinde, turist sayısının giderek arttığını ve bu artışın coğrafi ve dönemsel olarak yığınlaşarak gerçekleştiğini ve ülke ekonomisinin turizme bağımlılığının önemini koruduğunu söyleyebiliriz. $\mathrm{Bu}$ hususlar sürdürülebilir turizm politikaları ve planları çerçevesinde değerlendirildiğinde, popüler destinasyonlara olan ilginin sürekli arttığı ve buralardaki taşıma kapasitelerinin çok üstünde turist kabul etme durumunda kaldıkları görülmektedir (Tosun ve Jenkins, 1996:523). Diğer bir ifade ile ülke turizmi büyümektedir ve ekonomik nedenlerle bu büyüme kamu tarafından sürekli olarak teşvik edilmektedir. Bununla birlikte bu büyüme sürdürülebilir değildir çünkü hem mekânsal hem de dönemsel olarak yığınlaşmakta ve turizme konu olan kaynakları geri dönülmez bir şekilde tahrip etmektedir (Kervankıran, 2015:607).

$\mathrm{Bu}$ gidişatı değiştirme yönündeki strateji, plan ve politikalar ise henüz başarılı olamamıştır. Geleneksel olarak merkezi düzeyde, yerelin katılımı olmadan hazırlanan statik ve kapsamlı turizm 
master planları sürdürülebilir turizmi gerçekleştirmede etkin olamamıştır. Dolayısıyla ülkemizde turizm planlamasında bir değişime ihtiyaç duyulmaktadır. Yukarıda belirtildiği gibi sürdürülebilirlik odaklı turizm planlaması, kaynak değerlerin kaybedilmesi ve taşıma kapasitesinin aşılması gibi tehditlerin bertarafinda etkili olan en önemli araçlardan birisidir. Sürdürülebilir turizm planlaması; esnek, katılımcı ve stratejik niteliği ile Türkiye' deki turizm planlaması için önemli fırsatlar sunmaktadır (Tosun, 2008:9).

\section{Politika Belgelerinin İncelenmesi}

\subsection{Onuncu Kalkınma Planı}

Türkiye'de turizm politikaları uzun süre ana bir politika belgesi olmadan yürütülmüştür. Bu dönemde turizm politikalarının ana belirleyicisi kalkınma planları ve bu alanda toplanan özel ihtisas komisyonu (ÖIK) raporları olmuştur. "Sürdürülebilir turizm” kavramı ilk olarak Dokuzuncu Kalkınma Planı Turizm Özel İhtisas Komisyonu Raporunda kullanılmıştır (DPT, 2007). Onuncu Kalkınma Planı'nda ise turizmde sürdürülebilirlik temel bir ilke olarak ortaya konulmuştur. Bu Planda iki farklı paragrafta sürdürülebilir turizm ile ilgili ifadelere yer verilmiştir. Bunlardan ilki önceki plan döneminde gerçekleştirilen faaliyetler açıklanmış ${ }^{1}$, diğerinde ise sürdürülebilir turizmin yaygınlaştırılması plan dönemi politikaları arasında sıralanmışıı² (Kalkınma Bakanlığı, 2013:113-114). Onuncu Kalkınma Planı Turizm Özel İhtisas Komisyonu Raporu'nda ise turizm için aşağıdaki vizyonu belirlemiştir:

Türkiye'de turizm sektörü, sürdürülebilirlik ilkesini benimseyerek ziyaretçi saylsı ve turizm gelirlerinde dünyadaki ilk beş ülke arasında yerini alacak, turizm değer zincirindeki tüm unsurlarında, eğitilmiş nitelikli işgücü ve düzeyi gittikçe yükselen teknik altyapı, tesis ve servisleri ile uluslararası bir marka olacaktır.

Aynı Raporda on başlık altında turizme yönelik hedefler ve eylemler sıralanmıştır. Sürdürülebilir turizm de bu başlıklardan birisi olup bunun altında iki hedef ve sekiz eyleme yer verilmiştir (Çizelge 1). Özellikle doğal, tarihi ve kültürel çevrenin korunması politikası çerçevesinde Türkiye, turizmin uzun erimli çevresel, sosyo-kültürel ve ekonomik sürdürülebilirliğini sağlamak üzere yeni girişimleri hızlandırma eğilimindedir (Kalkınma Bakanlığı, 2014b:xiv).

Çizelge 1. Özel İhtisas Komisyonu Raporunda Sürdürülebilir Turizm Kararları

\begin{tabular}{|c|c|}
\hline Hedefler & Eylemler \\
\hline $\begin{array}{l}\text { 1. Turizm faaliyetleri; doğa, kültür ve } \\
\text { sosyal yapıyı koruyarak, döviz ve } \\
\text { istihdam boyutları ile ekonomik } \\
\text { gelişmeye katkı sağlayacak şekilde } \\
\text { talebi örgütleyerek, sektörün } \\
\text { gelişimine imkân verecek uygulamaları } \\
\text { da barındıran ve bütünleşebilen } \\
\text { katılımcı yaklaşımla yürütülecektir. } \\
\text { 2. Sürdürülebilir turizm yönetimi } \\
\text { benimsenecek, uygun olan yörelerde } \\
\text { farklı turizm türlerinin geliştirilmesi } \\
\text { için gerekli altyapı oluşturularak } \\
\text { uygulamalar gerçekleştirilecektir. }\end{array}$ & $\begin{array}{l}\text { 1. Yörelerin fiziksel planlarının yeniden yapılmasına devam } \\
\text { edilmesi, yörelerin/bölgelerin master planlarının söz konusu } \\
\text { perspektif doğrultusunda revize edilmesi, } \\
\text { 2. Planlamanı̈n bütüncül ve esnek bir yaklaşımla gerçekleştirilmesi, } \\
\text { 3. Yörelerin taşıma kapasitelerinin, geliştirilmesi öngörülen turistik } \\
\text { ürün dikkate alınarak belirlenmesi, } \\
\text { 4. Farklı yörelerin turizme açılmasında veya yörelerde mevcut } \\
\text { turistik ürünün geliştirilmesinde, sürdürülebilirliği sağlayan proje } \\
\text { ve faaliyetlerin desteklenmesi, } \\
\text { 5. Yeni turizm işletmeleri kurulması için verilecek izinlerde, } \\
\text { yörenin taşıma kapasitesinin ve koruma-kullanma dengesinin } \\
\text { dikkate alınması, } \\
\text { 6. Turizmde sürdürülebilir enerji ve atık yönetimi sistemlerinin } \\
\text { hayata geçirilmesi, }\end{array}$ \\
\hline
\end{tabular}

\footnotetext{
${ }^{1}$ Paragraf 868. Sürdürülebilir turizmin özendirilmesi amacıyla, 2008 yılında çevreye duyarlı konaklama tesislerinin standartları belirlenmiş ve belgeleme çalışmalarına başlanmıştır. Turizm merkezlerinde artan yapılaşma, altyapı eksikliği ve çevre sorunlarının giderilmesi, yatırımların turizm odaklı gelişme planlarına uyumunun sağlanması önem arz etmektedir.

${ }^{2}$ Paragraf 877. Çevreye duyarlı ve sorumlu turizm anlayışı kapsamında sürdürülebilir turizm uygulamaları geliştirilecek, turizmin sosyokültürel ve çevresel olumsuzlukları azaltılacaktır.
} 
7. Turizm bölgelerindeki işletmelerde dışarıya bağımlılı̆̆ı azaltan ve çevreye duyarlı yenilenebilir enerji üretimi ve yönetim sistemleri için teşvik verilmesi,

8. Turizm bölgelerinde verimli atık yönetim sistemlerinin yaygınlaştırılması.

Kalkınma planlarında sürdürülebilir turizme artan vurguya rağmen özel ihtisas komisyonu isimleri belirlenirken "sürdürülebilir turizm" ismi kullanılmamıştır. Çevre ve doğal kaynaklar, toprak ve su kullanımı, sosyal güvenlik ve sağlık konularında "sürdürülebilirlik kavramı" komisyonların isminde yer alırken, turizm konusunda bu tercih edilmemiştir (Kalkınma Bakanlığı, 2018c:7). Gelecek yıllarda turizm ile ilgili plan hazırlık çalışmalarının "sürdürülebilir turizm" başlığı ile yapılması bu eksikliği giderebilecektir.

\subsubsection{Türkiye Turizm Stratejisi ve Eylem Planı}

Türkiye Turizm Stratejisi (2023) ve Türkiye Turizm Stratejisi Eylem Planı (2007/2013) 28.02.2007 tarihli ve 2007/4 sayılı Yüksek Planlama Kurulu Kararı ile onaylanmış ve 02/03/2007 tarih ve 26450 sayılı Resmi Gazete'de yayınlanarak yürürlüğe girmiştir. Bu belgeler ile 2023 yılında 63 milyon turist, 86 milyar ABD Doları dış turizm geliri ve turist başına yaklaşık 1.350 ABD Doları harcama hedeflenmiştir.

Söz konusu Strateji (Kültür ve Turizm Bakanlığı, 2007a) ve Eylem Planı'nda (Kültür ve Turizm Bakanlığı, 2007b) bir yandan turizmin geliştirilmesi hedefi benimsenirken aynı zamanda turizmin kullandığı kıt kaynakların korunması da dikkate alınmış ve bu yönüyle sürdürülebilir turizm açısından önemli bir çerçeve oluşturmuştur. İki politika belgesinin birbiri ile tutarlı ve eşgüdüm içinde hazırlanması ve politikaların hayata geçirilmesi açısından eylem planı yaklaşımının benimsenmesi de olumlu bir adımdır. Bu şekliyle stratejik yaklaşımı benimseyen belgelerde ayrıca stratejik planlama sürecinin önemi ve bunun sürdürülebilir turizm yönetimi için etkin bir araç olduğu kabul edilmiştir. Strateji dokümanında sürdürülebilir turizm yaklaşımının benimsenerek istihdamın artırılması ve bölgesel gelişmede turizmin öncü bir sektör konumuna ulaştırılması amaçlanmıştır.

Bu bölümde öncelikle TTS kapsamında, BMÇP tarafından belirlenen sürdürülebilir turizmin 12 hedefinin ne düzeyde ele alındığı incelenmiştir. Bu incelemede BMÇP hedeflerinin tanımında yer alan anahtar kelimelerin dokümanda kullanılma sıklığı ve ana başl1klarda yer verilme durumuna bağlı bir ölçek (yok, düşük, orta, yüksek) kullanılmıştır.

Çizelge 2 genel olarak incelendiğinde TTS'de sürdürülebilir turizmin ekonomik boyutunun yüksek, çevresel boyutunun orta ve sosyal boyutunun düşük düzeyde ele alındığını söyleyebiliriz. Bunun yanında Türkiye Turizm Stratejisi Eylem Planı (2007-2013) eylemleri incelendiğinde 172 Eylemden 11'inin sürdürülebilirlik hedefleri ile uyumlu olduğu görülmektedir (TÜSİAD, 2012:52). Esasında bu pencereden bakıldığında ülkemizde sürdürülebilir turizm planlamasına ilişkin durum tam olarak gelişmiş̧ olmasa da önemli adımların atıldığı anlaşılmaktadır. Bununla birlikte ülkemizdeki genel planlama süreçleri incelendiğinde, planlama hususundaki kıt kaynağın plan yapılma durumu ya da planların kalitesi olmadığı bilinmektedir. Zira ülkemizde en azından mevzuat bakımından bir planlama zorunluluğu vardır ve plan yapma yönünde yeterli teknik kapasite oluşmuştur. Ancak, hazırlanan planların uygulanması, izlenmesi ve değerlendirmesinde çok ciddi aksaklıklar yaşanmaktadır. Mevcut durumda birçok turizm alanı çeşitli ölçeklerde planlara sahip olmasına rağmen taşıma kapasitelerinin 
çok üstünde ziyaretçiyi kabul etmekte ya da kontrolsüz bir şekilde artan ve denetlenemeyen yapı stokuna maruz kalmaktadır.

Planların uygulanmama sorununun nedenleri incelendiğinde aynı konuda birden fazla mevzuatın olması (çok hukukluluk), turizm dahil sektörel planların mekânsal planlarla eşgüdümünün sağlanamaması, plan uygulama araçlarının tanımlanmamış olması, planlara yönelik izleme ve değerlendirme süreçlerinin takip edilmemesi, çok fazla plan değişikliğinin yapılması ve planlama sürecine halkın katılımının sağlanamaması başlıca nedenler olarak gösterilmektedir (Çevre ve Şehircilik Bakanlığı, 2017; Sarı, Yener ve İnan, 2018).

Çizelge 2. TTS'nin sürdürülebilir turizm hedefleri itibarıyla değerlendirilmesi

\begin{tabular}{|c|c|c|c|}
\hline $\begin{array}{l}\text { Sürdürülebilir } \\
\text { turizm hedefi }\end{array}$ & Hedef açıklaması & $\begin{array}{l}\text { TTS'de } \\
\text { kullanım }\end{array}$ & Kullanılan ifade \\
\hline $\begin{array}{l}\text { Ekonomik } \\
\text { süreklilik }\end{array}$ & $\begin{array}{l}\text { Turizm destinasyonlarının ve } \\
\text { işletmelerinin uzun vadede } \\
\text { fayda sağlamaya ve büyümeye } \\
\text { devam etmesi için } \\
\text { sürekliliklerini ve } \\
\text { rekabetçiliklerini sağlamak }\end{array}$ & Yüksek & $\begin{array}{l}\text { - "hizmet kalitesinin ... süreklilik arz eden bir yapıya } \\
\text { kavuşturulması ve turizmde sürekli gelişme kavramının } \\
\text { yerleşmesi" }\end{array}$ \\
\hline Yerel refah & $\begin{array}{l}\text { Ziyaretçilerin yerel } \\
\text { harcamalarını artırmak da dâhil } \\
\text { olmak üzere ev sahibi } \\
\text { destinasyona katkısını azami } \\
\text { düzeye çıkarmak }\end{array}$ & Yüksek & $\begin{array}{l}\text { - "yerel ve bölgesel kalkınmada turizmin güçlü bir araç } \\
\text { olarak kullanılması" } \\
\text { - "yerel halkın kalkınmasına katkı sağlayacak el sanatları } \\
\text { ve yöresel örneklerin sunulduğu atölyeler" } \\
\text { _ "Yerel düzeyde kişisel gelirlerin ... artmasına" }\end{array}$ \\
\hline $\begin{array}{l}\text { Ziyaretçi } \\
\text { memnuniyeti }\end{array}$ & $\begin{array}{l}\text { Irk, cinsiyet, engellilik gibi } \\
\text { konularda ayrımcıllk } \\
\text { yapmadan, bütün ziyaretçilere } \\
\text { güvenli ve tatmin edici bir } \\
\text { deneyim sunmak }\end{array}$ & Orta & $\begin{array}{l}\text { - "müşteri memnuniyetinin maksimum düzeye } \\
\text { çıkarılması" }\end{array}$ \\
\hline Sosyal eşitlik & $\begin{array}{l}\text { Yoksullara sunulan firsatların, } \\
\text { çeşitlerin ve hizmetlerin } \\
\text { iyileştirilmesi de dâhil olmak } \\
\text { üzere turizmden elde edilen } \\
\text { ekonomik ve sosyal faydaların } \\
\text { genele adil bir şekilde } \\
\text { dağıtımını gözetmek } \\
\end{array}$ & Yok & \\
\hline $\begin{array}{l}\text { İstihdam } \\
\text { kalitesi }\end{array}$ & $\begin{array}{l}\text { Irk, cinsiyet, engellilik gibi } \\
\text { konularda ayrımcilığa mahal } \\
\text { vermeden, ücret ve hizmet } \\
\text { kalitesinin artırılması da dâhil } \\
\text { olmak üzere turizm tarafından } \\
\text { yaratılan yerel istihdamın } \\
\text { sayısını ve kalitesini artırmak }\end{array}$ & Yüksek & $\begin{array}{l}\text { - "işgücü kalitesinin artırılması" } \\
\text { - "işgücüne ilişkin minimum kalite standartları } \\
\text { belirlemek" } \\
\text { - "işgücü kalitesinin arttırılması amacıyla çalışmalar } \\
\text { yapılması" } \\
\text { - "işgücünün ve yönetimin etkinliğinin geliştirilmesi” }\end{array}$ \\
\hline Yerel kontrol & $\begin{array}{l}\text { Turizmin diğer paydaşlarıyla } \\
\text { istişare içinde planlama, } \\
\text { yönetim ve bölge turizminin } \\
\text { gelişimi konusunda yerel } \\
\text { yönetimleri süreçlere dâhil } \\
\text { etmek ve yetkilerini artırmak }\end{array}$ & Yüksek & $\begin{array}{l}\text { - "altyapı ve çevre sorunlarının yerel yönetimlerin ve } \\
\text { özel sektörün de katkılarıyla çözümlenmesi” } \\
\text { - "merkezi ve yerel yönetimler arasında dengeli bir görev } \\
\text { ve yetki bölüşümünün yapılması" } \\
\text { - "yapılacak çalışmalara yerel yönetimlerin ve sivil } \\
\text { toplum kuruluşlarının dahil edilmesi"” } \\
\text { - "yerel yönetimler ve Valilik ile işbirliği içerisinde } \\
\text { planlama çalışmaları yapılması" }\end{array}$ \\
\hline $\begin{array}{l}\text { Kültürel } \\
\text { zenginlik }\end{array}$ & $\begin{array}{l}\text { Ev sahibi topluluklara özgü } \\
\text { kültür, gelenek ve tarihi mirasa } \\
\text { saygı duymak ve güçlendirmek }\end{array}$ & Düşük & $\begin{array}{l}\text { - "kültürel ... değerlerini koruma-kullanma dengesi } \\
\text { içinde kullanmayı" } \\
\text { - "Yerel halkın soyut ve somut kültürel mirasın değeri ve } \\
\text { korunması konusunda bilinçlendirilmesi" }\end{array}$ \\
\hline $\begin{array}{l}\text { Fiziki } \\
\text { bütünlük }\end{array}$ & $\begin{array}{l}\text { Kentsel ve kırsal alanların } \\
\text { kalitesini muhafaza etmek ve } \\
\text { güçlendirmek, çevrenin fiziki } \\
\text { ve görsel bakımdan } \\
\text { bozulmasını engellemek }\end{array}$ & Düşük & $\begin{array}{l}\text { - "turizm bölgelerinin sürdürülebilirlik perspektifi içinde } \\
\text { yeniden ele alınarak planlanması ve kaliteli yaşanabilir } \\
\text { çevreler oluşturulması" } \\
\text { - "Fiziki planlama uygulanması ile ilgili eksikliği çeşitli } \\
\text { yasal koordinasyon düzenlemelerle ortadan kaldırılması" }\end{array}$ \\
\hline $\begin{array}{l}\text { Biyolojik } \\
\text { çeşitlilik }\end{array}$ & $\begin{array}{l}\text { Doğal alanların, habitatın ve } \\
\text { yaban hayatının korunmasını }\end{array}$ & Orta & $\begin{array}{l}\text { - "biyolojik çeşitliliği koruyarak eko-turizmin } \\
\text { yaygnnlaştırılması" }\end{array}$ \\
\hline
\end{tabular}




\begin{tabular}{|c|c|c|c|}
\hline $\begin{array}{l}\text { Sürdürülebilir } \\
\text { turizm hedefi }\end{array}$ & Hedef açıklaması & $\begin{array}{l}\text { TTS'de } \\
\text { kullanım }\end{array}$ & Kullanılan ifade \\
\hline & $\begin{array}{l}\text { desteklemek ve olası zararı } \\
\text { asgariye indirmek }\end{array}$ & & $\begin{array}{l}\text { - "yaban hayatına sahip olan bölgede, habitatlar ve } \\
\text { ekosistemler bozulmadan sürdürülebilir bir turizm } \\
\text { yaklaşımı sunulması" } \\
\text { - "Yaban Hayatı Koruma Alanları ... ile birlikte } \\
\text { bölgenin eko-turizm odaklı geliştirilmesiyle } \\
\text { bütünleştirilmesi" } \\
\text { - "çeşitlilik anlayışı içerisinde doğal kaynakları ekolojik } \\
\text { ve ekonomik verimlilik ilkesi kapsamında korunması ve } \\
\text { kullanılması" }\end{array}$ \\
\hline $\begin{array}{l}\text { Toplumsal } \\
\text { refah }\end{array}$ & $\begin{array}{l}\text { Sosyal bozulma ve istismara } \\
\text { yol açmadan sosyal yapı ve } \\
\text { kaynaklara, imkânlara, yaşam } \\
\text { destek sistemlerine erişim de } \\
\text { dâhil olmak üzere yerel halkın } \\
\text { yaşam kalitesini muhafaza } \\
\text { etmek, iyileştirmek }\end{array}$ & Düşük & $\begin{array}{l}\text { - "Sektörle ilgili tüm yatırımları ülkedeki refah ve } \\
\text { gelişmiş̧lik düzeyi dengesizliklerini azaltıcı doğrultuda } \\
\text { yönlendiren" } \\
\text { - "çarpık kentleşme ve yapılaşmayı önleyen, bozulmuş } \\
\text { olan kent ve kentsel mekanları iyileştiren" }\end{array}$ \\
\hline $\begin{array}{l}\text { Kaynak } \\
\text { verimliliği }\end{array}$ & $\begin{array}{l}\text { Turizm firma ve hizmetlerinin } \\
\text { gelişim ve işletmesinde sınırlı } \\
\text { ve yenilenemeyen kaynakların } \\
\text { kullanımını asgariye indirmek }\end{array}$ & Yüksek & $\begin{array}{l}\text { - "sınırlı turizm kaynaklarının en etkin bir şekilde } \\
\text { kullanılması” } \\
\text { - "Doğal kaynakları ekolojik ve ekonomik verimlilik } \\
\text { ilkesine bağlı olarak sürdürülebilirlik ilkeleri } \\
\text { çerçevesinde koruyan ve kullanan” } \\
\text { - "turizm kaynaklarını koruma ve dengeli kalkınma } \\
\text { anlayışı içinde kullanan" }\end{array}$ \\
\hline $\begin{array}{l}\text { Çevresel } \\
\text { saflik }\end{array}$ & $\begin{array}{l}\text { Turizm işletmelerinden ve } \\
\text { ziyaretçilerden kaynaklanan } \\
\text { hava, su, kara kirliliğini ve atık } \\
\text { üretimini asgariye indirmek }\end{array}$ & Orta & $\begin{array}{l}\text { - "İşletme yönetiminde çevreyi dikkate alan bu } \\
\text { çerçevede en az enerji ve doğal kaynaklar kullanarak en } \\
\text { az atık üreten sistemlerin araştırılması" } \\
\text { - "atık su arıtma ve deşarjı, katı atık toplama ve bertaraf } \\
\text { tesisleri gibi altyapı tesislerinin plan, proje ve inşaatları } \\
\text { gerçekleştirilecektir" }\end{array}$ \\
\hline
\end{tabular}

Kaynak: İlk iki sütun Sarışık ve Genç (2017:62)’ten alınmış, diğerleri yazar tarafından üretilmiştir.

Dolayısıyla burada salt doküman üzerinden yapılan inceleme bu strateji ve eylemlerin sürdürülebilir turizm açısından aynen sahada gözlemlenebilmesi anlamına gelmemektedir. Bu açıdan bu çalışmanın neticesinde ortaya konulan taşıma kapasitesi hesapları, stratejik planlama yaklaşımı, izleme ve değerlendirme ile paydaş katılımının sürdürülebilir turizm uygulamaları için çok önemli olduğu tespiti ülkemiz için daha çok geçerlidir. Bu çerçevede politika tasarımında bu konulara özel önem verilmesinin yerinde olacağı değerlendirilmektedir. $\mathrm{Bu}$ dört unsur itibarıyla Strateji dokümanı incelendiğinde ise;

Stratejik planlama (yüksek): Dokümanda planlama yaklaşımının stratejik hale dönüştürülmesi temel hedeflerden birisi olarak gösterilmiş ve eylem planında stratejik planlamaya ilişkin münferit bir eyleme yer verilmiştir. Stratejik planlamanın esnek, şeffaf, hesap verebilir, yönetim ve uygulama etaplarında katılımcı ve sürdürülebilir gelişim niteliklerine sahip bir planlama olduğu dile getirilerek turizm planlamasının bu yaklaşımı benimsemesi gerektiği vurgulanmıştır. Burada her ne kadar bazı temel kavramlar (vizyon, plan senaryoları, stratejiler, duyuru ve paylaşımlar) kullanılarak planların stratejik planlama niteliği ön plana çıkarılmaya çalışılsa da dokümanda belirtilen hususların birçoğu tipik planlama sürecinin tekrarından oluşmaktadır.

Paydaş katılımı (yüksek): Strateji, katılımcılığı en önemli unsurlardan biri olarak ortaya koymuş ve kurumsallaşarak genişleyen bir katılımcılık mekanizması öngörmüştür. Bu yönüyle çağdaş strateji ve politika belgelerinden belirgin bir farkı yoktur. Bununla birlikte Stratejide ortaya konulan yönetişim ve katılım mekanizmaları hayata geçmemiştir. Ulusal ve yerel düzeylerdeki konseyler toplanmamış ve kamu kesimi, özel sektör ile halk arasındaki etkileşimi sağlayacak platformlar kurulamamıştır. 
Taşıma kapasitesi (düşük): Bu hususa Stratejide özel bir yer verilmemekle birlikte 2023 hedefleri arasında "mevcut ve yeni gelişim bölgelerinde taşıma kapasitesi ölçümü" yapılacağı ifade edilmiş ve uygulamaların "taşıma kapasitelerini aşmadan" yapılacağı dile getirilmiştir. Turizm planları incelendiğinde taşıma kapasitesinin planlarda yer bulduğu ancak uygulamada taşıma kapasitesini geçen destinasyonlar olduğu görülmektedir. Zira yukarıda hem dönemsel hem de coğrafi olarak turizmin dağılımına bakıldığında turist çeken mevcut destinasyonların giderek genişlediği, turizmin yaygınlaşarak değil yığınlaşarak büyüdüğü görülmüştür.

İzleme ve değerlendirme (orta): Strateji dokümanı izleme ve değerlendirme konusunda çeşitli hedefler ortaya koymaktadır. Ulusal Turizm Veri Bankası Birimi ve Ulusal Turizm Belgeleme (Akreditasyon) Biriminin oluşturulması ile ölçümleme kriterlerinin geliştirilmesi ile düzenli raporlama yapılması bunlardan bazılarıdır. Turizm planlamasında ölçme, izleme ve değerlendirme bir yandan politikaların ne düzeyde hayata geçtiğinin takip edilmesini diğer yandan ise turizmin olumsuz etkilerinin kontrol altına alınabilmesi açısından önem arz etmektedir. Sağlıklı bir izleme ve değerlendirme sisteminin oluşturulması ancak güncel, düzenli ve güvenilir istatistiklerin üretilmesi ile mümkün olabilecektir. Bununla birlikte ülkemizde turizme ilişkin verilerin toplanmasında birden fazla kurumun yetkili olması (bakanlık, belediye ve meslek örgütleri), veri tanımlarında eksiklik ve tutarsızlık ve güvenirlilik başta olmak üzere sorunlar devam etmektedir. Ancak başta coğrafi bilgi sistemleri olmak üzere coğrafi ve idari kayıt verilerinin tutulmasına yönelik gelişmeler bu sorunların çözümü için firsatlar sunmaktadır. Bu altyapılar ile toplanan verilerin bir araya getirilmesi, düzenli raporlanması ve politikaların bu çerçevede gözden geçirilmesine yönelik ihtiyaç devam etmektedir.

\subsection{Turizm Şûrası Komisyon Raporları ve Eylem Planı}

Turizm sektörünün mevcut durumunun değerlendirilmesi ve geleceğe yönelik ulusal bir turizm politikasının oluşturulabilmesi amacıyla, 01 - 03 Kasım 2017 tarihleri arasında kamu kurum ve kuruluşları, turizm meslek örgütleri, sivil toplum kuruluşları, turizm sektörü ve akademik camianın katılımı ile III. Turizm Şûrası ${ }^{3}$ düzenlenmiştir. Şûrada sürdürülebilir turizm vurgusu ön plana çıkmıştır. Zira, Şûranın temel amac1 "sürdürülebilir bir turizm endüstrisine sahip olma" olarak belirlenmiştir. Şûra kapsamında belirlenen 13 başlık $^{4}$ arasında "turizmde ürün çeşitliliği ve sürdürülebilirlik" başlığına yer verilmiş ve bu konuda bir komisyon toplanarak sonuç raporu hazırlanmıştır. Bu komisyonun sürdürülebilir turizmi bir turizm çeşidi olarak ele alma eğiliminde olduğu görülmüştür. Bununla birlikte hem bu komisyon hem de diğer komisyonlarda sürdürülebilir turizme yönelik alınan kararlar Çizelge 3’te sunulmuştur.

Çizelge 3. Şura komisyon raporlarında sürdürülebilir turizme ilişkin atıflar

\begin{tabular}{ll}
\hline \multicolumn{1}{c}{ Komisyon adı } & \multicolumn{1}{c}{ Sürdürülebilir turizme yönelik kararlar } \\
\hline Çevre-planlama-altyap1 & - sürdürülebilir turizm için çevre stratejisinin oluşturulması \\
& - sürdürülebilir gelişme ve taşıma kapasitesi yaklaşımının geliştirilmesi \\
& - sürdürülebilir turizm anlayışının planlama sistemine entegre edilmesi \\
\hline İç turizm & - sürdürülebilir turizm esasları doğrultusunda yoğun biçimde deniz-kum-güneş \\
& temelinde gerçekleşen iç turizmin, alternatif turizm türlerine ve Türkiye'nin tüm \\
& bölgelerine yaygınlaştırılması \\
\hline Konaklama sektörü & - sürdürülebilir turizm stratejilerinin hazırlanması \\
& - sürdürülebilir turizm kapsamında, denizin ve çevrenin korunmasına yönelik \\
& denetimlerin yapılması \\
\hline
\end{tabular}

${ }^{3}$ I. Şûra 1998 yılında, II. Şura 2002 yılında Ankara'da gerçekleştirilmiştir.

${ }^{4}$ Turizm politikaları, turizmde örgütlenme ve destinasyon yönetimi, turizmde ürün çeşitliliği ve sürdürülebilirlik, çevreplanlama-altyapı, yatırım-teşvik-finansman, konaklama sektörü, seyahat acentacılığı ve ulaşım, tanıtma ve pazarlama, dijital turizm ve inovasyon, turizm eğitimi, istihdamı ve turist rehberliği, yerel yönetimler ve turizm, iç turizm ve gastronomi turizmi. 


\begin{tabular}{|c|c|}
\hline Komisyon adı & Sürdürülebilir turizme yönelik kararlar \\
\hline Tanitma-pazarlama & $\begin{array}{l}\text { - turizm türlerine yönelik sürdürülebilirlik ilkesi doğrultusunda stratejik eylem } \\
\text { planlarının yapılması }\end{array}$ \\
\hline Turizm politikaları & $\begin{array}{l}\text { - turizmde sürdürülebilir gelişme ilkelerinin yerleştirilmesi için ilgili paydaşlarla } \\
\text { işbirliği yapılması } \\
\text { - turizm sektöründeki paydaşların çevre duyarlılığına ve sürdürülebilir turizm } \\
\text { odaklı faaliyetlere ağırlık vermelerinin teşvik edilmesi }\end{array}$ \\
\hline $\begin{array}{l}\text { Turizmde örgütlenme } \\
\text { ve destinasyon } \\
\text { yönetimi }\end{array}$ & $\begin{array}{l}\text { - sürdürülebilir kalkınmayı da destekleyen destinasyon yönetimi yaklaşımının } \\
\text { geliştirilmesi }\end{array}$ \\
\hline $\begin{array}{l}\text { Turizmde ürün } \\
\text { çeşitliliği } \\
\text { ve sürdürülebilirlik }\end{array}$ & $\begin{array}{l}\text { - ulusal sertifikasyon kurumları oluşturularak sürdürülebilir ürünlerin ulusal } \\
\text { firmalarca denetlenerek etiketlenmesi } \\
\text { - sürdürülebilirlik kavramına ilişkin farkındalığın artırılması } \\
\text { - sürdürülebilir turizm projelerinin yerel halk ile entegre olmasının sağlanması } \\
\text { - yerel turizm paydaşlarında sürdürülebilirlik bilincinin yaratılması } \\
\text { - sürdürülebilirlik konusunda mevzuatın geliştirilmesi } \\
\text { - sürdürülebilir turizm ürünlerinin etkili pazarlamasının yapılması }\end{array}$ \\
\hline
\end{tabular}

Kaynak: Yazar tarafindan hazırlanmışıtır.

Komisyon çalışmaları üzerinden yürütülen toplantılar neticesinde mevzuat-örgütlenme, tanıtma-pazarlama, planlama-altyapı, teşvik ve eğitim-istihdam başlıkları altında 92 eylemden oluşan bir Eylem Planı hazırlanmıştır. Söz konusu eylem planında doğrudan sürdürülebilir turizmle ilişkili olan eylemler aşağıda sunulmaktadır:

- Eylem 59: Turizmde ürün çeşitliliğinin sürdürülebilir turizm anlayışı çerçevesinde planlanması ve yaygınlaştırılması - Yerel kalkınma ve istihdamın geliştirilmesi, bölgelerarası gelişmişlik dengesizliğinin azaltılması amacıyla kitle turizminin yanısıra ülkemizin turizme hizmet edebilecek tüm zenginliklerinden sürdürülebilir turizm yaklaşımı çerçevesinde yararlanılması için çalışmalar yapılacaktır.

- Eylem 66: Turizm alanlarının ilan sürecinde taşıma kapasitesi ve koruma-kullanma dengesinin gözetilmesi - Kültür ve Turizm Bakanlığınca ilan edilecek turizm merkezleri ile kültür ve turizm koruma ve gelişim bölgelerinin tespitinde çevresel değerlerin sürdürülebilirliği dikkate alınarak turizm sektöründe değerlendirilmesi için taşıma kapasitesi ve koruma-kullanma dengesini gözeten etüt çalışmaları yapılacaktır.

- Eylem 77: Sürdürülebilir turizm kapsamında, çevrenin korunması, çevre bilincinin artırılması ve özendirilmesine yönelik sertifikasyon sistemlerinin geliştirilmesi ve yaygınlaştırılması Yenilenebilir enerji kaynaklarının kullanılmasıyla ilgili destek ve teşvik mekanizmaları oluşturularak, atık organik gıda maddelerinin komposta dönüştürülmesi, atık su ve yemeklerin değerlendirilmesi vb. çevre korumacı yaklaşımları kullanan tesislerin yaygınlaştırılması ve teşvik edilmesine yönelik çalışmalar yürütülecektir.

\subsection{Sürdürülebilir Kalkınma Belgeleri}

TTS'nin yanında ülkemizdeki sürdürülebilir kalkınma girişimlerini tespit ve teşvik etmek amacıyla yapılan diğer çalışmalar incelenerek turizmin sürdürülebilir kalkınma gündeminde nasıl ele alındığı değerlendirilebilir. Bu kapsamda "Türkiye Sürdürülebilir Kalkınma Raporu Geleceği Sahiplenmek 2012 Raporu” ile "Sürdürülebilir Kalkınma Hedefleri Kapsamında Türkiye'nin Mevcut Durum Analizi Projesi Taslak Raporu” incelenmiştir. 
Çizelge 4. Turizme ilişkin sürdürülebilir kalkınma hedefleri itibarıyla Türkiye'deki durum

\begin{tabular}{|c|c|c|}
\hline Amaç & Hedef & Türkiye'deki durum \\
\hline $\begin{array}{l}\text { SKA } 8 \text { Kesintisiz, kapsayıcı ve } \\
\text { sürdürülebilir ekonomik } \\
\text { büyümenin, tam ve üretken } \\
\text { istihdamın ve herkes için insana } \\
\text { yakışır işlerin desteklenmesi }\end{array}$ & $\begin{array}{l}\text { Hedef 8.9: 2030'a kadar istihdam } \\
\text { yaratan ve yerel kültür ve ürünlerini } \\
\text { teşvik eden sürdürülebilir turizmin } \\
\text { desteklenmesi için politikalar } \\
\text { oluşturulması ve uygulanması }\end{array}$ & $\begin{array}{l}\text { Deniz ve güneş turizmi dişında } \\
\text { turizmin çeşitlendirilmesi ve } \\
\text { ülke geneline yayılması önem } \\
\text { taşımaktadır. }\end{array}$ \\
\hline $\begin{array}{l}\text { SKA 12: Sürdürülebilir Tüketim } \\
\text { ve Üretim }\end{array}$ & $\begin{array}{l}\text { Hedef 12.b: İstihdam yaratan ve yerel } \\
\text { kültür ve ürünlerini teşvik eden } \\
\text { sürdürülebilir bir turizm için } \\
\text { sürdürülebilir kalkınma etkilerini } \\
\text { denetlemeye olanak sağlayan araçlar } \\
\text { geliştirilmesi ve uygulanması }\end{array}$ & $\begin{array}{l}\text { Turizmde } \\
\text { gündemiyle çeşitlenme } \\
\text { taşımaktadır. }\end{array}$ \\
\hline
\end{tabular}

Kaynak: Kalkınma Bakanlığı, 2017

İlk Raporda ülkemizdeki turizme ilişkin önemli tespitler yer almaktadır. Türkiye'de turizm sektörünün dinamik ve rekabetçi özelliğe sahip olduğunu belirten Raporda, alternatif çeşitliliğin sunulabilmesi halinde sürdürülebilir turizm modelinin hayata geçirilebileceği ifade edilmiştir (Kalkınma Bakanlığı, 2012:7). Raporda ayrıca turizm sektörünün cari açı̆̆ı azaltma kapasitesi ile ekonomik kalkınmada önemli bir rolü olmasının yanında, sürdürülebilir kalkınma için sunduğu fırsatlar nedeniyle sosyal ve çevresel gelişmeleri de olumlu etkileyebileceği dile getirilmiştir (a.g.e.:13). Bunun yanında, başta kıyı alanları olmak üzere turizmin özel çevre koruma bölgeleri, yaban hayatı, yöresel bitki örtüsü üzerindeki etkilerinin dikkate alınmasına yönelik uyarılara yer verilmiştir (a.g.e.:29,49,50). İkinci raporda ise 2030 Sürdürülebilir Kalkınma Gündemi kapsamında belirlenen 17 Sürdürülebilir Kalkınma Amacı ve 169 Sürdürülebilir Kalkınma Hedefinin hangilerinin Türkiye için geçerli olduğu ve bu hedef itibarıyla mevcut durum tespit edilmektedir. Bu kapsamda Türkiye'deki turizme yönelik iki geçerli hedef olduğu raporlanmıştır (Çizelge 4).

\subsection{BGUS ve Bölge Planları}

Bir bölgenin sadece turizm faaliyetleri ile gelişmesini beklemek mümkün olmayabilir. Ancak bu bölgenin turizm potansiyeli ile diğer varlıklarını harekete geçirmesi ve bölgesel gelişme açısından önemli bir başarı sergilemesi mümkündür (Boyacıoğlu, 2015:198). Turizmin birçok sektörle geri ve ileri bağlantılarının olması bu gelişmeyi mümkün kılmaktadır. Zira, turizmin gelişmesine yönelik alt ve üst yapıya yapılan yatırımlar turizme girdi üreten sektörleri harekete geçirerek turizmin başlatıcı bir rol oynamasını desteklemektedir (İncekara, 2001:28). Bu durum gelişmiş ülkeler/bölgeler için sektörel açıdan geliştirici bir etki oluştururken, gelişmekte olan ülkeler/bölgeler için kalkınmaya hız verici ve tamamlayıcı bir nitelik arz etmektedir. Özellikle merkez üretim ve sanayi sektörleri bakımında yeterli kaynak ve gelişme olanağı bulunmayan ve bu alanların dışında ya da uzağında kalan bölgeler için alternatif bir kalkınma potansiyeli sunmaktadır. İsviçre'de Alpler ve ABD'de Las Vegas gibi endüstri alanlarının dışında olup turizm ile gelişme ivmesi kaydeden bölgeler bulunmaktadır (Oktayer vd., 2007:117-119). Ancak turizm gelişmesi ile hızlı bir şekilde gelişen (altyapı yatırımları, konaklama tesisleri ve alan düzenlemeleri) ve kaynak değerlerini (doğal, tarihi, kültürel, peyzaj) yok ederek ya da tahrip ederek daha fazla çöküntüye uğrayan bölgeler de bulunmaktadır. Bu nedenle bölgesel gelişmenin sağlanabilmesi için sürdürülebilir bir turizm planlaması gereklidir.

Turizmin bölgesel gelişme açısından önemi ülkemizde de hem sektörel hem de bölgesel politika belgelerinde ayrı ayrı vurgulanmıştır. TTS'nin iki yatay hedefinden birisi sürdürülebilirlik iken diğeri 
bölgesel gelişmedir. Onuncu Kalkınma Planı Turizm Özel İhtisas Komisyonu Raporu'nda temel amaç5 ifadesinde hem sürdürülebilirlik ilkesine hem de bölgesel kalkınma hedefine yer verilmiştir (Kalkınma Bakanlığı, 2014b:xv). III. Turizm Şûrası'nda da sürdürülebilir turizm ile bölgesel kalkınmanın bir arada ele alınması gerektiği değerlendirilmiştir (Kültür ve Turizm Bakanlığı, 2018:103).

Bununla birlikte yukarıda belirtildiği gibi 1982 sonrası gelişmelere bakıldığında birkaç destinasyona sıkışan turizm faaliyetlerinin genel olarak bölgeler arası gelişmişlik farklılıklarını azaltmada etkili olamadığı görülmüştür. Diğer yandan turizmin geliştiği bölgelerde de turizm gelirlerinin ve turist sayısının artırılması temel amaç olarak belirlenmiş, turizm gelirlerinin adil dağılımı ve yerel ekonominin geliştirilmesi ihmal edilmiştir (Dinçer ve Çetin, 2015:191). Bu çerçevede, konuyu bir de bölgesel gelişme politikaları bağlamında değerlendirerek bu alandaki strateji ve planların turizme bakış açısını anlamak üzere BGUS ile bölge planlarında sürdürülebilir turizm yaklaşımının nasıll ele alındığ incelenmiştir.

BGUS'ta sektörel ve tematik stratejilerle bölgesel stratejilerin uyumunu güçlendirmede, merkezi ve yerel idarelerin hizmetlerini yönlendirmede, kaynak tahsisi ve uygulamayı etkinleştirmede işlevsel olacak yatay amaçlar belirlenmiştir. "Bölgelerin rekabet gücünün artırılması" bu yatay amaçlardan birisi olup "turizm potansiyelinin yerel ve bölgesel kalkınma için etkili kullanımı" hedefi bu yatay amaç altında ele alınmıştır (Kalkınma Bakanlığı, 2014a: 121). BGUS'un turizm ile ilgili temel tespiti TTS ile uyumludur. Buna göre turizm sektörünün çeşitlendirilmesi ve farklı bölgelerdeki potansiyellerin değerlendirilmesi bölgesel gelişme açısından önemli firsatlar sunmaktadır (a.g.e.:70). Bunun yanında ortalama turist harcamalarının düşüklüğü, turizmin belirli alanlara sıkışmış olması, yatak kapasitesi ve işletmelerin kalite sorununa yer verilmiştir. Ayrıca, sürdürülebilir turizmle doğrudan ya da dolaylı olan konular gündeme getirilmiştir. Turizmin sürdürülebilir gelişmesi ile uyumlu büyüme odaklarının oluşturulması, turizmin kirletici etkilerinin dikkate alınması, turizmin coğrafi ve dönemsel olarak yaygınlaştırılması, biyolojik çeşitliliğin korunması bu konulardan bazılarıdır. Doğal ve kültürel değerlere sahip alanlarda "sürdürülebilir turizm" yaklaşımının kullanılması da tavsiye edilmektedir (a.g.e.:132). Ağırlıklı vurgu ise deniz-kum-güneş turizminin alternatif turizm türleri ile çeşitlendirilmesine ve böylelikle turizmin ülke geneline yayılarak bölgesel gelişme farklılıklarını azaltmada etkin bir araç konumuna gelmesine yapılmıştır.

Genel olarak bakıldığında ise BGUS’ta sürdürülebilir kalkınmanın içselleştirildiği ve ilgili tüm sektörlerde bu bakış açısının dikkate alındığı söylenebilir. Buna ilave olarak "Sürdürülebilir Çevre ve Yeşil Ekonominin Desteklenmesi” başlığı da turizmde olduğu gibi yatay amaçlar arasında sıralanmıştır. Sürdürülebilirlik genel yaklaşımına rağmen izleme göstergeleri arasında turizm ile ilgili olarak sadece "Turizm yatırım-işletme ve belediye belgeli yatak sayısı" göstergesine yer verilmiştir. Bu şekilde turizmi geliştirmeye aday Anadolu kentlerindeki gelişmenin izlenmesinin hedeflendiği söylenebilir.

Benzer bir analiz bölge planları üzerinden yapıldığında, 5 bölge planı hariç tüm planlarda sürdürülebilirlikle ilgili bir ana başlık ya da temel öncelik olduğu görülmüştür (Çizelge 5). Bu başl1klardan çoğu çevresel sürdürülebilirliğe vurgu yapmakta olup, az sayıda ekonomik sürdürülebilirlik boyutu da öne çıkmıştır. Altı bölge planında sürdürülebilirlik yaklaşımının orta düzeyde ele alındığı geri kalan tüm planlarda ise sürdürülebilirlik kavramına yüksek önem verildiği anlaşılmıştır. Sadece

\footnotetext{
${ }^{5}$ Türkiye'de turizmde, nitelikli işgücü, tesis ve hizmet kalitesiyle uluslararası bir marka haline gelmek; daha üst gelir grubuna hitap edecek şekilde turizm ürün ve hizmetlerini çeşitlendirmek ve iyileştirmek; turizm değer zincirinin her bileşeninde kaliteyi artırarak sürdürülebilirlik ilkesi çerçevesinde bölgesel kalkınmada öncü bir sektör haline gelmek temel amaçtır.
} 
TRAKYAKA (Tekirdă̆, Edirne, Kırklareli) Bölge Planı ile DAKA (Van, Muş, Bitlis, Hakkari) bölge planlarında sürdürülebilir turizme bir başlık ya da öncelik altında yer verilmiştir. Bununla birlikte 13 bölge planında "sürdürülebilir turizm" kavramı doğrudan yer almaktadır. Bölge planlarında turizm sektörüne bakış açısının sürdürülebilir turizm çerçevesinde değerlendirildiğinde 11 bölge planının yüksek, 8 bölge planının orta ve 7 bölge planının düşük düzeyde sürdürülebilirlik yaklaşımına sahip olduğu görülmüştür.

Sürdürülebilir turizmin planlardaki derinliği ile bölge turizminin sektör içindeki payı birlikte incelendiğinde sürdürülebilir turizmin bir alternatif turizm yaklaşımı olarak turizmin geliştirilmesi istenilen bölgelerde kullanılan bir yaklaşım olduğu görülmektedir. Kitle turizminin yaygın olduğu (yüzde 10 ve üzeri) BAKA, İSTKA ve GEKA bölge planlarında sürdürülebilir turizm vurgusu düşük ya da orta düzeydedir. Turizm pazarından aldığı pay bakımından ilk beşte olan bölgeler arasında bu genellemeyi bozan tek bölge İzmir olmuştur.

Genel olarak değerlendirildiğinde ise sürdürülebilir kalkınma yaklaşımının BGUS'ta olduğu gibi neredeyse tüm bölge planlarında kabul edildiği ve içselleştirildiği görülmektedir. Bununla birlikte her ne kadar turizmde sürdürülebilirliğe vurgular yapılmış olsa da altyapı, tanıtım, markalaşma ve kalite çabaları sürdürülebilir turizm gündeminin önünde yer almaktadır. Buna rağmen TTS ve BGUS'un sürdürülebilir turizm ve turizmin bölgesel eşitsizlikleri giderme rolüne önemli ölçüde atıf yapıldığ1 görülmüştür. Diğer yandan, kalkınma ajansları tarafından turizmin sadece bölgelerarası değil bölge içi eşitsizliklerin de dengeleyicisi olarak görüldüğü anlaşılmıştır. Bu açıdan bakıldığında 2014 yılında onaylanan bölge planları ile Tosun ve Jenkins (1996) tarafindan dile getirilen bölgesel planlama eksikliğinin giderilmesi adına önemli bir aşama kaydedildiği söylenebilir. Ancak planlamadaki bu çabalara rağmen yine aynı çalışmada önerilen bölgesel ölçekte turizm faaliyetlerinin yönetimine ilişkin idari sahiplenme (a.g.e.:530) sağlanamadığından uygulamada eksiklikler devam etmektedir. Ayrıca, bölge planlarının alt ölçeklerinde gerçekleştirilecek turizm planlarında katılım ve yönetişim modelleri eksik olduğu için sürdürülebilir turizme dönük sonuçlar istenilen düzeyde alınamamıştır (Hatipoğlu, Alvarez ve Ertuna, 2016:316).

Burada yürütülen içerik analizleri bize genel olarak sürdürülebilir kalkınma, özel olarak ise sürdürülebilir turizm gündeminin ülkemiz tarafından yakından takip edildiği, bunların merkezi düzeyde özenli bir şekilde politika dokümanlarına yansıtıldığını göstermiştir. Sürdürülebilir turizm artık her ölçekte ilgili tüm aktörlerin üzerinde ortaklaştığı temel bir ilke ve hareket noktası olmuştur. Politika belgelerinde sürdürülebilirlik vurgusunun ve hedeflerinin giderek artmasına rağmen, henüz sürdürülebilir turizm yaklaşımının yaygın uygulamaya geçemediği ve turizm sektöründe sürdürülebilirliğin içselleştirilmediği anlaşılmaktadır. Turizm politikalarında ve planlarında hala karar alma süreçlerinde merkezi yönetimin ağırlı̆̆ görülmektedir ve yerel aktörler sürdürülebilir turizm gündeminden ve önceliklerinden yeterince haberdar değildir. Zira, Dünya Ekonomik Forumu tarafindan 2017 yılında yayınlanan "Seyahat ve Turizm Rekabetçilik Raporu”nda "sürdürülebilir çevre”, "doğal kaynaklar", "insan kaynağı ve işgücü” gibi 14 başlıkta belirlenen göstergeler çerçevesinde yapılan ülkeler sıralamasında Türkiye 136 ülke arasında sürdürülebilir çevre başlığında 112., doğal kaynaklar başlığında 70., genel sıralamada ise 44. sırayı almıştır (Kültür ve Turizm Bakanlığı, 2018:101). 
Çizelge 5. Bölge planlarının sürdürülebilirlik ve sürdürülebilir turizm bakımından değerlendirilmesi

\begin{tabular}{|c|c|c|c|c|c|c|c|}
\hline & & Sürdürülebilir kalkınma & & & & & Sürdürülebilir turizm \\
\hline Bölge planı & $\begin{array}{l}\text { Sektör } \\
\text { pay1 } \\
(2015)^{*}\end{array}$ & Başlık/ Öncelik & İçerik & $\begin{array}{l}\text { Başlık/ } \\
\text { Öncelik }\end{array}$ & Kavram & İçerik & Notlar \\
\hline BAKA & $45,7 \%$ & Sürdürülebilir yerel kalkınma, sürdürülebilir çevre & Yüksek & Yok & Yok & Orta & Turizmin yaygınlaştırılması ve çeşitlendirilmesi amaçlanmıştır. \\
\hline İSTKA & $23,5 \%$ & $\begin{array}{l}\text { Keyifle yaşanan, özgün kentsel mekânlar ve sürdürülebilir } \\
\text { çevre }\end{array}$ & Yüksek & Yok & Yok & Düşük & İstanbul'un küresel turizm merkezi olması hedeflenmiştir. \\
\hline GEKA & $15,2 \%$ & Yaşanabilir mekânsal ve sürdürülebilir çevre & Yüksek & Yok & Var & Orta & Dört mevsim turizm hedefi benimsenmiştir. \\
\hline İZKA & $3,8 \%$ & Sürdürülebilir üretim ve hizmet sunumu, sürdürülebilir çevre & Yüksek & Yok & Var & Yüksek & $\begin{array}{l}\text { Sürdürülebilir turizmin uygulanması ve yaygınlaştırılması } \\
\text { amaçlanmıştır. }\end{array}$ \\
\hline AHİKA & $2,5 \%$ & Sürdürülebilir ekonomik büyüme & Yüksek & Yok & Yok & Orta & Kalitenin ve rekabet gücünün artırılmasına odaklanılmıştır. \\
\hline ANKARA KA & $1,8 \%$ & Sürdürülebilir büyüme & Yüksek & Yok & Var & Yüksek & Sürdürülebilir turizm ilkelerine atıf yapılmıștır. \\
\hline GMKA & $1,4 \%$ & Yok & Orta & Yok & Var & Yüksek & Sürdürülebilir turizm ilkelerine atıf yapılmıştır. \\
\hline BEBKA & $1,2 \%$ & $\begin{array}{l}\text { Dengeli mekânsal gelişme ve sürdürülebilir çevre, kırsal } \\
\text { yaşamın sürdürülebilirliğinin sağlanması }\end{array}$ & Yüksek & Yok & Yok & Orta & Tanıtım, altyapı ve kaliteye odaklanılmıştır. \\
\hline MARKA & $0,9 \%$ & Çevresel sürdürülebilirliği sağlamak & Yüksek & Yok & Yok & Yüksek & Turizmin yeniden şekillendirilmesi hedeflenmiştir. \\
\hline DOKA & $0,9 \%$ & Yaşanabilir mekânlar ve sürdürülebilir çevre & Orta & Yok & Yok & Orta & Bölge halkının refahının artırılması perspektifi kullanılmıştır. \\
\hline ÇKA & $0,8 \%$ & Çevresel sürdürülebilirlik & Yüksek & Yok & Yok & Orta & Eko-turizm sürdürülebilir turizm yerine kullanılmıştır. \\
\hline İKA & $0,5 \%$ & $\begin{array}{l}\text { Sürdürülebilir kırsal kalkınmanın sağlanması, sürdürülebilir } \\
\text { kentleşmenin sağlanması, doğal kaynakların sürdürülebilir } \\
\text { kullanılması }\end{array}$ & Yüksek & Yok & Var & Düşük & Altyapı ve markalaşma önceliklendirilmiştir. \\
\hline MEVKA & $0,5 \%$ & Yok & Yüksek & Yok & Yok & Düşük & Alternatif turizm firsatları öne çıkarılmıştır. \\
\hline KARACADAĞ & $0,4 \%$ & Sürdürülebilir gelişme ve yeşil büyüme & Yüksek & Yok & Var & Yüksek & Geliştirme ve kalitenin artırılması öne çıkarılmıștır. \\
\hline BAKKA & $0,2 \%$ & Sürdürülebilir sosyal kalkınma & Yüksek & Yok & Yok & Orta & Çeşitlendirme, kalite ve marka konuları önceliklendirilmiştir. \\
\hline DOĞAKA & $0,2 \%$ & Yok & Orta & Yok & Var & Düşük & $\begin{array}{l}\text { Turizm potansiyelinin ekonomiye } \\
\text { kazandırılması öne çıkarılmıştır. }\end{array}$ \\
\hline TRAKYAKA & $0,2 \%$ & $\begin{array}{l}\text { Doğal kaynakların korunarak sürdürülebilir yönetimi } \\
\text { sağlanacaktır }\end{array}$ & Yüksek & Var & Var & Yüksek & $\begin{array}{l}\text { "Turizmin bölgesel işbirlikleri çerçevesinde sürdürülebilir gelişimi } \\
\text { sağlanacaktır" başlığı kullanılmıştır }\end{array}$ \\
\hline DAKA & $0,2 \%$ & $\begin{array}{l}\text { Sürdürülebilir çevre yönetiminin sağlanması, sürdürülebilir } \\
\text { kırsal kalkınma programlarının hazırlanması }\end{array}$ & Orta & Var & Yok & Yüksek & $\begin{array}{l}\text { "Bölge'nin Turizm Çeșitliliği Potansiyelinin Sektöre Kazandırılması } \\
\text { ve Turizm Gelirlerinin Sürdürülebilir Bir Şekilde Artırılması" başlığı } \\
\text { kullanılmıştır. }\end{array}$ \\
\hline ZAFER & $0,2 \%$ & Yok & Yüksek & Yok & Var & Yüksek & Altyap1, kalite ve çeşitlendirme önceliklendirilmiştir. \\
\hline OKA & $0,2 \%$ & $\begin{array}{l}\text { Biyolojik çeşitliliğin korunması ve sürdürülebilirliğinin } \\
\text { sağlanması }\end{array}$ & Yüksek & Yok & Var & Orta & Çeşitlendirme ve tanıtıma odaklanılmıştır. \\
\hline KUDAKA & $0,1 \%$ & Yok & Orta & Yok & Yok & Orta & Turizmin sosyo-ekonomik faydası dikkate alınmıştır. \\
\hline DİKA & $0,1 \%$ & Sürdürülebilir çevre ve mekânsal yerleşim & Yüksek & Yok & Var & Yüksek & Sektörler arası entegrasyon, kalitenin artırılması amaçlanmıştır. \\
\hline ORAN & $0,1 \%$ & Sürdürülebilir çevre ve enerji & Yüksek & Yok & Yok & Düşük & Altyapı, tanıtım ve markalaşma önceliklendirilmiştir. \\
\hline SERKA & $0,1 \%$ & Çevresel sürdürülebilirlik & Yüksek & Yok & Yok & Düşük & Altyapı ve tanıtım odaklıdır. \\
\hline FKA & $0,1 \%$ & Sürdürülebilir ekonomi & Orta & Yok & Var & Yüksek & Sürdürülebilir Turizm Stratejisi ve Eylem Planı hazırlanmıştır. \\
\hline KUZKA & $0,1 \%$ & Doğal kaynakların sürdürülebilir kullanılması & Yüksek & Yok & Var & Yüksek & Eko-turizm sürdürülebilir turizm yerine kullanılmıştır. \\
\hline
\end{tabular}

* Toplam geceleme içindeki pay (2015)

Kaynak: Kalkınma Bakanlı̆̆ı, 2018b 


\section{Tartışma ve Sonuç}

Çalışmada kalkınma planları ve plan hazırlıkları kapsamında üretilen ÖİK raporları incelendiğinde sürdürülebilir turizm kavramına, ilkelerine ve yaklaşımına yer verildiği görülmektedir. Bununla birlikte plan ve hazırlık raporlarında hala kitle turizmi ve herşey dahil sistemi ile bunların olumsuz etkileri açık bir şekilde tartı̧̧maya açılmamış, öncelikli strateji olarak yatırımların artırılması hedefi korunmuştur. Bunun sonucunda her ne kadar planlı kalkınma döneminde turizm arz ve talebinde muazzam bir artış gerçekleşmiş olsa da özellikle bazı destinasyonlarda turizmin sürdürülebilirliği ve etkinliği sorgulanır hale gelmiştir (Dinçer ve Çetin, 2015:191).

TTS sürdürülebilir turizm ve hedefleri itibarıyla değerlendirildiğinde ise Stratejinin önemli ölçüde sürdürülebilirliği dikkate aldığını söyleyebiliriz. Bununla birlikte söz konusu Stratejinin mevzuat ve uygulama boyutları ile gerçek hayata yansıma düzeyinde istenilen sonuçlar elde edilememiştir. $\mathrm{Bu}$ çerçevede sahada yürütülen ve onaylanan turizm planları, arazi kullanım planları ile son dönemde yürürlüğe giren birincil ve ikincil mevzuatın ayrıca değerlendirilmesi gerektiği düşünülmektedir. Sürdürülebilirliğin boyutları itibarıyla bakıldığında ise Stratejinin, ekonomik boyuta çevresel ve toplumsal boyutlardan daha fazla ağırlık verdiği görülmüştür. Bu durum turizmin ülkemizde dış ticaret dengesindeki cari açığı kapatmaya odaklı ekonomik bir sektör olarak görülmesi ile ilişkilidir. Turizme verilen bu rol, turizm gelirlerinin turist sayısıyla ve turizm arzının da yeni yatırımlarla artırılması ezberinin bozulamamasına ve çevresel ve toplumsal sürdürülebilirliğin göz ardı edilmesine yol açmaktadır.

Turizm Şurası Raporu ve Eylem Planı, sürdürülebilir turizmi en kapsamlı şekilde ele alan ulusal doküman olmuştur. Diğer dokümanlardan farklı olarak burada sürdürülebilirliğin her üç boyutuna da atıf yapılmıştır. Ancak bu dokümanlar benzer diğer şura organizasyonlarında (şehircilik, kültür, tarım, orman ve su) da olduğu gibi iyi niyet belgeleri niteliğindedir. Dolayısıyla icracı bakanlıkların bu dokümanları hayata geçirmeme ve bunlarda zikredilen hedeflerin uygulanmama riski bulunmaktadır.

Öte yandan sürdürülebilir kalkınma gündemini takip bakımından hazırlanmış olan ulusal belgelerde turizme dönük daha objektif ve gerçekçi bir yaklaşım sergilenmiştir. Turizmin mekânsal yığınlaşması ve kaynak değerler üzerindeki baskısı açıkça ortaya konulurken, sürdürülebilirlik ilkesine riayet edilmesi halinde turizmin ekonomik, sosyal ve çevresel gelişmeye olumlu katkı sağlayacağı vurgulanmıştır.

Ulusal dokümanlarda turizmin bölgesel kalkınmaya katkısı öne çıkarıldığı gibi BGUS ve bölge planlarında da sürdürülebilir turizme temel amaçlar arasında yer verildiği görülmüştür. Bu sonuç sürdürülebilir turizm ile bölgesel kalkınma arasındaki karşılıklı bağımlılık ilişkisini teyit etmektedir. Zira ülkemizde turizmin sürdürebilir bir nitelik kazanabilmesi için mekânsal olarak ülke sathında yayılması ve kaynak değerler üzerindeki baskısını azaltması gerekmektedir. Ayrıca sürdürülebilir turizm yaklaşımında turizmin getirilerinden yerel halkın faydalanma düzeyi yüksektir ve sürdürülebilir turizm, sosyo-ekonomik kalkınma oluşturma potansiyeli ile hem bölgeler arası hem de bölge içi gelişmişlik farklarının azaltılabilmesi adına etkin bir araç olarak kullanılabilecektir.

Temel ulusal ve bölgesel politika belgelerinde ve planlarda sürdürülebilir turizme yer verilmesi uygulamada aynı düzeyde bir etkinin olacağı anlamına gelmemektedir. Zira ülkemizde planlama alanında en temel sorunlardan birisi plansızlık ya da yanlış planlamadan ziyade planların hayata geçmemesi ya da eksik veya hatalı uygulanmasıdır. Dolayısıyla; ulusal, sektörel ve bölgesel politika 
belgelerinde sürdürülebilir turizme ve sürdürülebilir turizm planlamasına yönelik atıflar yer almasının yanında bunların hayata geçirilmesine yönelik somut tedbirleri ve iyi uygulama örneklerini içeren, özellikle yerel yönetimler ve idareler için yol gösterici nitelikte olan yönlendirici kılavuzlar hazırlanmalıdır.

Halihazırda yerelde turizmde sürdürülebilirliği önemseyen aktörler dahi bu süreci nasıl başlatacağı ve nasıl yürüteceği konusunda yeterli bilgiye sahip değildir. Diğer bir ifadeyle, dokümanlarda bu konunun önemi ve gerekliliğinin (neden sorusuna cevap) anlatılmasının yerine pratik uygulama ve örneklerine (nasıl sorusuna cevap) üretilmesinin yararlı olacă̆ 1 düşünülmektedir. Diğer yandan, sürdürülebilir turizmin sadece sürdürülebilir, ekolojik ya da yeşil turizm ürünleri/paketleri ile gerçekleştirilmesi mümkün değildir. Sürdürülebilir turizm, sürdürülebilir kalkınma ilkesi ile şekillenmiş bir fiziki çevre, toplumsal katılım ve adalet ile mümkündür. Bu nedenle sürdürülebilir turizm bütüncül bir yaklaşımla ele alınmalı ve uygulamaya geçilmelidir.

Bu çerçevede kamu kesimi teoriden pratiğe geçişte sürdürülebilir turizme ilişkin somut önlemler ve teşvik edici araçlar ortaya koymalıdır. Ayrıca, yerel halkın planlama süreçlerine katılımı, yerel ve bölgesel ihtiyaçlara göre farklılaşan esnek planlama ve yerindenlik ilkesi çerçevesinde yerel kurum ve kuruluşlara yetki devri hususlarına yönelik düzenleyici tedbirler alınmalıdır (Çetinel ve Yolal, 2009:47). Diğer yandan turizm planlarında sürdürülebilirlik ilkesine bağlı stratejik yaklaşım benimsenmelidir. Turizm arz ve talebi için alternatif gelişme senaryoları ekonomik, sosyal ve çevresel boyutlar itibarıyla değerlendirilerek en etkin ve etkili alternatif olarak tercih edilmelidir. Ayrıca hem destinasyon hem de bölgesel düzeyde taşıma kapasiteleri hesaplanarak uygulama planları için bu eşik değerin geçilmemesine dikkat edilmelidir. Taşıma kapasitesinin yanında sürdürülebilir turizme ilişkin takip edilecek performans göstergeleri planlama sürecinin ilk aşamasından itibaren belirlenmeli ve bunların belirli periyotlarla ölçülmesi ve raporlanması temin edilmelidir.

Sonuç olarak, ilk dönemde kitle turizmine alternatif bazı turizm türlerinin ortaya atılması ya da işletme bazında bazı ekolojik uygulamaların hayata geçirilmesi ile sınırlandırılan sürdürülebilir turizm çerçevesi zaman içerisinde genişlemeye devam etmiştir. Bununla birlikte sürdürebilir turizm ülkemizde henüz içselleştirilmemiş ve turizm süreçlerinin tamamına yaygınlaştırılamamıştır. $\mathrm{Bu}$ kapsamda sürdürülebilir turizm ve turizm planlamasına yönelik uygulamanın teşvik edilmesi ve destinasyon düzeyinden bölgesel ölçeğe kadar iyi uygulama örneklerinin yaygınlaştırılmasına yönelik ihtiyaç devam etmektedir.

\section{Teşekkür}

Bu çalışma, Ankara Üniversitesi Beşeri ve İktisadi Coğrafya Doktora Programı kapsamında 2017-2018 Güz döneminde aldığım 03026072 - Sürdürülebilir Turizm Yönetimi dersi için hazırlanan dönem ödevi geliştirilerek tamamlanmıştır. Gerek söz konusu ders süresince sağlamış olduğu kıymetli bilgiler ve çalışmanın geliştirilmesi yönünde verdiği görüşler gerekse bu çalışmanın yayınlanması yönünde yaptığı teşvikten ötürü Ankara Üniversitesi Dil ve Tarih-Coğrafya Fakültesi Coğrafya Bölümü Başkanı Sayın Prof. Dr. Mehmet Somuncu'ya teşekkür ederim. 


\title{
Sustainable Tourism Planning in National and Regional Policy Documents in Turkey
}

\author{
Volkan Idris Sari*a
}

\section{EXTENDED ABSTRACT}

\section{Introduction}

The concept of sustainable tourism was first emerged in close connection with the concept of sustainable development (Torres-Delgado and Palomeque, 2014:124). Sustainable tourism requires the sustainable growth of both economic and social outcomes of tourism and the sustainable use of the environmental and natural resources (Liu, 2003:462). The World Tourism Organization (WTO) defines sustainable tourism as " Tourism that takes full account of its current and future economic, social and environmental impacts while addressing the needs of visitors, the industry, the environment and host communities." (UNWTO, 2017:12).

Planning is the most important tool for preventing uncontrolled growth of tourism depending on the increase in demand (Özgüç, 2007: 182). Therefore, one of the most important issues for the sustainable tourism literature is the planning of sustainable tourism. With an unplanned supply, it can be self-destructing. It is accepted that sustainable tourism can promote and support conservation, regeneration and economic development, and can also help the improvement of the quality of life for visitors and host communities (Connell et al., 2009: 868). The main argument of sustainable tourism planning is that the socio-economic benefit that will occur with the planned tourism growth will spread to its surroundings with the participation of local community (Bardakoğlu, 2014: 126).

As the potential of damaging or even destroying resource values of tourism is understood in Turkey, the sustainable tourism agenda has started to be taken into consideration with a delay compared to global trend. Particularly in the post- 1980 period, the fact that mass tourism became the dominant tourism type through its promotion by public policies has led to the agglomeration of tourism in a very concentrated narrow space while threatening resource values. At this stage, it was understood that the growth of tourism was not sustainable, and for balancing this process priorities have been started to be determined with the main policy documents. In this study, the frequency of references to these priorities within the main policy documents on tourism is examined and the current state of sustainable tourism and sustainable tourism planning in Turkey at the policy level is evaluated.

\footnotetext{
* Corresponding Author: volkan.i.sari@gmail.com

a Ankara University, Graduate School of Social Sciences, Ankara, Turkey, http://orcid.org/0000-0001-7032-8069
} 


\section{Data and Methods}

In this study, data analysis, literature review and document analysis techniques are used. First, the tourism development process in Turkey is briefly explained and then the need for sustainable tourism is presented in terms of selected indicators at national level. The current situation and the growth of tourism sector in Turkey are examined through data driven from Turkish Statistical Institute (TUIK), Turkey Association of Travel Agents (TURSAB) and the main character of the tourism growth in Turkey are tried to be revealed by analyzing the data from the relevant ministries.

National, regional and sectoral policy documents in Turkey are reviewed in terms of sustainable tourism and sustainable tourism planning. In this context, document analysis method is used for the basic documents determining tourism policies. Beside development plans, Turkey's Tourism Strategy and Action Plan (TTS), Reports of 3rd Tourism Council, national documents on sustainable development, National Strategy for Regional Development (BGUS) and regional plans prepared according to 26 NUTS 2 regions are studied.

Document analysis is the process of analyzing concepts and materials related to the research subject (Gürbüz and Şahin, 2014: 182). In this framework, the frequency and the depth of using the term of "sustainable tourism planning" and its related concepts in policy documents are assessed by thematic content analysis method. Thematic content analysis (meta-synthesis) is to review documents within a specific field by using a qualitative approach that analyzes similarities and differences comparatively. In content analysis, it is recommended to use this method when there is a limited number of available documents (Çalık \& Sözbilir, 2014: 34).

The inability to handle all the policy documents related to tourism and the subjectivity of assessments during document analysis are limitations of this study. In addition, this study, which is limited to the analysis made through policy documents, can be followed by examining the case studies of sustainable tourism in Turkey. Following studies can be made to analyze in what extent these national and regional policy documents and plans reflected in implementation and how sustainable tourism can be moved from theory to practice, from policy level to project level through the success and the failures of these documents and plans.

\section{Results}

Over a long period of time tourism policies in Turkey has been carried out without a major policy document. The main determinant of tourism policies in this period was the development plans and the reports of the Special Expertised Committee assembled in this field. The concept of sustainable tourism was first used in the Report of Tourism Expertised Committee under the Ninth Development Plan (SPO, 2007). In the Tenth Development Plan (Ministry of Development, 2013), sustainability in tourism was set forth as a main principle. In the Report of Special Expertised Committee (Ministry of Development, 2014b), objectives and actions for tourism were listed under ten topics. Sustainable tourism was one of these topics, with two goals and eight actions under it.

TTS (Ministry of Tourism and Culture, 2017a) and the Action Plan (Ministry of Tourism and Culture, 2017b), on the one hand, anticipates the goal of improving tourism, on the other hand, takes the conservation of scarce resources of tourism into account. In this respect it created an important framework for sustainable tourism. Within the scope of TTS, the level of context referred to 12 objectives of sustainable tourism determined by the UNEP were examined. Analyzing the Table 1 in 
general, it can be argued that the economic dimension of sustainable tourism has higher frequency while the environmental dimension has medium and the social dimension has low frequencies. When actions under the TTS and the Action Plan were considered, it can be seen that 11 out of 172 actions are compatible with sustainability objectives (TUSİAD, 2012: 52).

Table 1. Evaluation of TTS with respect to sustainable tourism objectives

\begin{tabular}{|c|c|c|c|}
\hline $\begin{array}{l}\text { Sustainable } \\
\text { tourism aims }\end{array}$ & Explanation of the objective & $\begin{array}{l}\text { Level at } \\
\text { TTS }\end{array}$ & Referred context \\
\hline $\begin{array}{l}\text { Economic } \\
\text { Viability }\end{array}$ & $\begin{array}{l}\text { To ensure the viability and } \\
\text { competitiveness of tourism } \\
\text { destinations and enterprises, so that } \\
\text { they are able to continue to prosper } \\
\text { and deliver benefits in the long term }\end{array}$ & High & $\begin{array}{l}\text { - To provide a continuous structure of service } \\
\text { quality and to establish the concept of continuous } \\
\text { improvement in tourism }\end{array}$ \\
\hline $\begin{array}{l}\text { Local } \\
\text { Prosperity }\end{array}$ & $\begin{array}{l}\text { To maximize the contribution of } \\
\text { tourism to the prosperity of the host } \\
\text { destination, including the proportion } \\
\text { of visitor spending that is retained } \\
\text { locally }\end{array}$ & High & $\begin{array}{l}\text { - Using tourism as a powerful tool in local and } \\
\text { regional development } \\
\text { - Crafts and local workshops that will contribute to } \\
\text { the development of local people } \\
\text { - Increased personal income at local level }\end{array}$ \\
\hline $\begin{array}{l}\text { Visitor } \\
\text { Fulfillment }\end{array}$ & $\begin{array}{l}\text { To provide a safe, satisfying and } \\
\text { fulfilling experience for visitors, } \\
\text { available to all without } \\
\text { discrimination by gender, race, } \\
\text { disability or in other ways. }\end{array}$ & Medium & - maximizing customer satisfaction \\
\hline Social Equity & $\begin{array}{l}\text { To seek a widespread distribution of } \\
\text { economic and social benefits from } \\
\text { tourism throughout the recipient } \\
\text { community, including improving } \\
\text { opportunities, income and services } \\
\text { available to the poor. }\end{array}$ & No & \\
\hline $\begin{array}{l}\text { Employment } \\
\text { Quality }\end{array}$ & $\begin{array}{l}\text { To strengthen the number and quality } \\
\text { of local jobs created and supported } \\
\text { by tourism, including the level of } \\
\text { pay, conditions of service and } \\
\text { availability to all without } \\
\text { discrimination by gender, race, } \\
\text { disability or in other ways. }\end{array}$ & High & $\begin{array}{l}\text { - Improving labor quality } \\
\text { - Setting minimum quality standards for the } \\
\text { workforce } \\
\text { - Conducting studies to improve labor quality } \\
\text { - Improving the effectiveness of the workforce and } \\
\text { management }\end{array}$ \\
\hline Local Control & $\begin{array}{l}\text { To engage and empower local } \\
\text { communities in planning and } \\
\text { decision making about the } \\
\text { management and future development } \\
\text { of tourism in their area, in } \\
\text { consultation with other stakeholders. }\end{array}$ & High & $\begin{array}{l}\text { - Resolving infrastructure and environmental } \\
\text { problems with the contribution of local } \\
\text { governments and private sector } \\
\text { - A balanced division of tasks and powers between } \\
\text { central and local governments is aimed. } \\
\text { - Local governments and non-governmental } \\
\text { organizations will be included in the studies } \\
\text { - Planning studies to be carried out in cooperation } \\
\text { with local administrations and Governorate }\end{array}$ \\
\hline $\begin{array}{l}\text { Cultural } \\
\text { Richness }\end{array}$ & $\begin{array}{l}\text { To respect and enhance the historic } \\
\text { heritage, authentic culture, traditions } \\
\text { and distinctiveness of host } \\
\text { communities. }\end{array}$ & Low & $\begin{array}{l}\text { - Using cultural values in a balance of protection } \\
\text { and use } \\
\text { - Local people will be made aware of the value } \\
\text { and protection of abstract and concrete cultural } \\
\text { heritage }\end{array}$ \\
\hline $\begin{array}{l}\text { Physical } \\
\text { Integrity }\end{array}$ & $\begin{array}{l}\text { To maintain and enhance the quality } \\
\text { of landscapes, both urban and rural, } \\
\text { and avoid the physical and visual } \\
\text { degradation of the environment }\end{array}$ & Low & $\begin{array}{l}\text { - Re-planning tourism regions within the } \\
\text { sustainability perspective and creating quality } \\
\text { habitable environments } \\
\text { - Lack of implementation of physical planning will } \\
\text { be eliminated by various legal coordination } \\
\text { arrangements }\end{array}$ \\
\hline $\begin{array}{l}\text { Biological } \\
\text { Diversity }\end{array}$ & $\begin{array}{l}\text { To support the conservation of } \\
\text { natural areas, habitats and wildlife, } \\
\text { and minimize damage to them. }\end{array}$ & Medium & $\begin{array}{l}\text { - To promote eco-tourism by preserving biological } \\
\text { diversity } \\
\text { - A sustainable tourism approach will be offered in } \\
\text { the wild-life region without disturbing habitats and } \\
\text { ecosystems } \\
\text { - Integration of the region with eco-tourism } \\
\text { oriented development will be ensured with the } \\
\text { Wildlife Conservation Areas }\end{array}$ \\
\hline
\end{tabular}




\begin{tabular}{|c|c|c|c|}
\hline $\begin{array}{l}\text { Sustainable } \\
\text { tourism aims }\end{array}$ & Explanation of the objective & $\begin{array}{c}\text { Level at } \\
\text { TTS }\end{array}$ & Referred context \\
\hline & & & $\begin{array}{l}\text { - Within the concept of diversity, protecting and } \\
\text { using natural resources within the scope of } \\
\text { ecological and economic efficiency principle }\end{array}$ \\
\hline $\begin{array}{l}\text { Community } \\
\text { Wellbeing }\end{array}$ & $\begin{array}{l}\text { To maintain and strengthen the } \\
\text { quality of life in local communities, } \\
\text { including social structures and access } \\
\text { to resources, amenities and life } \\
\text { support systems, avoiding any form } \\
\text { of social degradation or exploitation. }\end{array}$ & Low & $\begin{array}{l}\text { - Directs all investments related to the sector to } \\
\text { reduce the welfare and development level } \\
\text { imbalances in the country. } \\
\text { - Prevents distorted urbanization and construction, } \\
\text { improves degraded cities and urban spaces }\end{array}$ \\
\hline $\begin{array}{l}\text { Resource } \\
\text { Efficiency }\end{array}$ & $\begin{array}{l}\text { To minimize the use of scarce and } \\
\text { non-renewable resources in the } \\
\text { development and operation of } \\
\text { tourism facilities and services. }\end{array}$ & High & $\begin{array}{l}\text { - The most effective use of limited tourism } \\
\text { resources } \\
\text { - Protecting and using natural resources within the } \\
\text { framework of sustainability principles based on } \\
\text { the principle of ecological and economic } \\
\text { efficiency } \\
\text { - Uses tourism resources in an understanding of } \\
\text { protection and balanced development }\end{array}$ \\
\hline $\begin{array}{l}\text { Environmental } \\
\text { Purity }\end{array}$ & $\begin{array}{l}\text { To minimize the pollution of air, } \\
\text { water and land and the generation of } \\
\text { waste by tourism enterprises and } \\
\text { visitors. }\end{array}$ & Medium & $\begin{array}{l}\text { - In this context, considering the environment in } \\
\text { business management, researching the systems } \\
\text { that produce the least waste by using the least } \\
\text { energy and natural resources } \\
\text { - Plans, projects and constructions of infrastructure } \\
\text { facilities such as waste water treatment and } \\
\text { discharge, solid waste collection and disposal } \\
\text { facilities will be realized. }\end{array}$ \\
\hline
\end{tabular}

Source: For first two columns Sarışık and Genç (2017:62)

TTS has also been reviewed in terms of four basic elements of sustainable tourism planning. In this document, the transformation of the planning approach into a "strategic planning" manner was named as one of the main objectives and the Action Plan a specific action on strategic planning. TTS suggests "participation" as one of the most important elements and envisages a participatory mechanism that is expanding through institutionalization. Although there is no specific reference to "carrying capacity" in the Strategy, among the 2023 objectives it is stated that "in existing and new tourism development regions carrying capacity measurement will be carried out" and "the implementations will be carried out without exceeding the carrying capacity". On the other hand, the strategy document sets out various objectives on data collection, "monitoring and evaluation".

At the Third Tourism Council, held in 2017, the emphasize on sustainable tourism came to the forefront. The main purpose of the Council has been announced as "to have a sustainable tourism industry" (Ministry of Tourism and Culture, 2018). Within the scope of the Council, one of 13 topics was identified as "Product Diversity and Sustainability in Tourism" and a final report has been prepared by a dedicated commission to this topic.

The Sustainable Development Report to Turkey (2012), which considers the tourism sector in Turkey as dynamic and competitive, states that the sustainable tourism model can be realized if the alternative diversity is ensured (Ministry of Development, 2012:7). In addition, the Report highlighted the importance of the negative impacts of tourism on the special environmental protection areas, especially coastal areas, wildlife and local vegetation. Draft Report on "Current Situation Analysis Project for Sustainable Development Goals in Turkey" has also listed prevailing goals of tourism in Turkey (Ministry of Development, 2017).

Other reviewed documents on sustainable tourism are on regional development including the National Strategy for Regional Development (BGUS) and regional plans (Ministry of Development, 2014a). Basic findings of BGUS on tourism are consistent with TTS. Accordingly, the diversification 
of tourism sector and the mobilization of potentials in different regions provide important opportunities for regional development. Establishing growth centers in consistent with the sustainable development of tourism, taking the contaminating effects of tourism into account, spreading tourism geographically and periodically, and preserving biodiversity are some of the findings stated in BGUS. It is also recommended to use a "sustainable tourism" approach in areas with natural and cultural values.

Reviewing regional plans, only TRAKYAKA (Tekirdağ, Edirne, Kirklareli) and DAKA (Van, Muş, Bitlis, Hakkari) regional plans have "sustainable tourism" under a specific section or a priority. Besides, the concept of "sustainable tourism" is directly mentioned in 13 regional plans. When the perspective of tourism sector in regional plans is evaluated within the framework of sustainable tourism, it is observed that 11 regional plans have high, 8 regional plans have medium and 7 regional plans have low level of sustainability approach (Table 2).

\section{Discussion and Conclusions}

In this study, it is observed that sustainable tourism concept, principles and approach are included in the developmental plans and the related committee reports. However, mass tourism and the all-inclusive system and their negative effects are not criticized in these plans and the reports, and the aim for continuous growth of investments is preserved. As a result of this, although there has been a tremendous increase in tourism supply and demand during the planned period of the Country, the sustainability and effectiveness of tourism are still questionable especially for some destinations (Dinçer \& Çetin, 2015: 191).

When TTS and its objectives are evaluated in terms of sustainable tourism, we can say that the Strategy shows a strong consideration of sustainability. However, the expected results in achieving to realize the Strategy in daily life with legislation and implementation dimensions could not be obtained. In terms of three dimensions of sustainability, it can be seen that the Strategy focuses more on the economic dimension than the environmental and social dimensions. This situation is related to the fact that tourism is perceived as an economic sector focused on closing the current deficit of foreign trade balance in Turkey. This role given to tourism, prevents to break the mould of increasing tourism revenues through raising the number of tourists and the tourism supply with new investments, and causes to neglect environmental and social sustainability.

The Tourism Council Report and the Action Plan is the national document which integrates sustainable tourism the most. Unlike other documents, all three dimensions of sustainability are referred in this one. However, it remains only as a declaration of goodwill as in other similar council organizations (urbanization, culture, agriculture, forestry and water). Therefore, there is the risk that the executing ministries may not put these documents into practice and their stated objectives may not be implemented.

On the other hand, a more objective and realistic approach for the tourism growth is exhibited in the national documents prepared to follow the sustainable development agenda. Not only these reports clearly reveal the spatial agglomeration of tourism and its pressure on resource values, but also it emphasizes that tourism would contribute positively to economic, social and environmental development if sustainability principles are respected. 
$\underline{\text { Table 2. Evaluation of regional plans in terms of sustainability and sustainable tourism }}$

\begin{tabular}{|c|c|c|c|c|c|c|c|}
\hline \multirow[b]{2}{*}{ Regional plan } & \multirow[b]{2}{*}{$\begin{array}{l}\text { Sector } \\
\text { ratio } \\
(2015)^{*} \\
\end{array}$} & \multicolumn{2}{|l|}{ Sustainable development } & \multicolumn{4}{|r|}{ Sustainable tourism } \\
\hline & & Heading/ Objective & Context & $\begin{array}{l}\text { Heading/ } \\
\text { Objective }\end{array}$ & Concept & Context & Notes \\
\hline BAKA & $45,7 \%$ & $\begin{array}{l}\text { Sustainable Local Development, Sustainable } \\
\text { Environment }\end{array}$ & High & No & No & Medium & It is aimed to expand and diversify tourism. \\
\hline İSTKA & $23,5 \%$ & $\begin{array}{l}\text { Enjoyable, Unique Urban Spaces and Sustainable } \\
\text { Environment }\end{array}$ & High & No & No & Low & Istanbul is aimed to be a global tourism center. \\
\hline GEKA & $15,2 \%$ & Livable Spatial and Sustainable Environment & High & No & Yes & Medium & Four seasons tourism destination is adopted. \\
\hline İZKA & $3,8 \%$ & $\begin{array}{l}\text { Sustainable Production and Service Delivery, } \\
\text { Sustainable Environment }\end{array}$ & High & No & Yes & High & It is aimed to implement and disseminate sustainable tourism. \\
\hline AHİKA & $2,5 \%$ & Sustainable Economic Growth & High & No & No & Medium & The focus is on increasing quality and competitiveness. \\
\hline Ankara KA & $1,8 \%$ & Sustainable Growth & High & No & Yes & High & Referred to sustainable tourism principles. \\
\hline GMKA & $1,4 \%$ & No & Medium & No & Yes & High & Referred to sustainable tourism principles. \\
\hline BEBKA & $1,2 \%$ & $\begin{array}{l}\text { Balanced Spatial Development and Sustainable } \\
\text { Environment, Ensuring the Sustainability of Rural Life }\end{array}$ & High & No & No & Medium & Focus is on publicity, infrastructure and quality. \\
\hline MARKA & $0,9 \%$ & Ensuring Environmental Sustainability & High & No & No & High & Main objective is reshaping tourism structure. \\
\hline DOKA & $0,9 \%$ & Livable Spaces and Sustainable Environment & Medium & No & No & Medium & $\begin{array}{l}\text { The perspective of increasing the welfare of the people of the region } \\
\text { was targeted. }\end{array}$ \\
\hline ÇKA & $0,8 \%$ & Sustainable Environment & High & No & No & Medium & Eco-tourism has been used instead of sustainable tourism. \\
\hline İKA & $0,5 \%$ & $\begin{array}{l}\text { Sustainable Rural Development, Sustainable } \\
\text { Urbanization, Sustainable Use of Natural Resources }\end{array}$ & High & No & Yes & Low & Infrastructure and branding are prioritized. \\
\hline MEVKA & $0,5 \%$ & No & High & No & No & Low & Alternative tourism opportunities were highlighted. \\
\hline KARACADAĞ & $0,4 \%$ & Sustainable Development and Green Growth & High & No & Yes & High & Development and quality improvement have been highlighted. \\
\hline BAKKA & $0,2 \%$ & Sustainable Social Development & High & No & No & Medium & Diversification, quality and brand issues are prioritized. \\
\hline DOĞAKA & $0,2 \%$ & No & Medium & No & Yes & Low & Bringing the tourism potential to the economy was emphasized. \\
\hline TRAKYAKA & $0,2 \%$ & $\begin{array}{l}\text { Sustainable Management by Conserving Natural } \\
\text { Resources }\end{array}$ & High & Yes & Yes & High & $\begin{array}{l}\text { "Sustainable development of tourism will be achieved within the } \\
\text { framework of regional cooperation" }\end{array}$ \\
\hline DAKA & $0,2 \%$ & $\begin{array}{l}\text { Ensuring Sustainable Environmental Management, } \\
\text { Preparation of Sustainable Rural Development Programs }\end{array}$ & Medium & Yes & No & High & $\begin{array}{l}\text { "Bringing the Region's Tourism Diversity Potential to the Sector and } \\
\text { Increasing Tourism Revenues in a Sustainable Way" title was used. }\end{array}$ \\
\hline ZEKA & $0,2 \%$ & No & High & No & Yes & High & Infrastructure, quality and diversification are prioritized. \\
\hline OKA & $0,2 \%$ & Conservation and Sustainability of Biodiversity & High & No & Yes & Medium & The focus is on diversification and promotion. \\
\hline KUDAKA & $0,1 \%$ & No & Medium & No & No & Medium & Socio-economic benefit of tourism is taken into consideration. \\
\hline DİKA & $0,1 \%$ & Sustainable Environment and Spatial Settlement & High & No & Yes & High & Intersectoral integration is aimed at increasing the quality. \\
\hline ORAN & $0,1 \%$ & Sustainable Environment and Energy & High & No & No & Low & Infrastructure, promotion and branding are prioritized. \\
\hline SERKA & $0,1 \%$ & Environmental Sustainability & High & No & No & Low & It focuses on infrastructure and publicity. \\
\hline FKA & $0,1 \%$ & Sustainable Economy & Medium & No & Yes & High & Sustainable Tourism Strategy and Action Plan was prepared. \\
\hline KUZKA & $0,1 \%$ & Sustainable Use of Natural Resources & High & No & Yes & High & Eco-tourism has been used instead of sustainable tourism. \\
\hline
\end{tabular}

* The ratio of the region in overall tourism nights (2015)

Source: Ministry of Development, 2018b 
As national documents highlight the contribution of tourism to regional development, sustainable tourism is included among the main objectives of BGUS and regional plans. This result confirms the interdependence between sustainable tourism and regional development. In order to achieve a sustainable nature of tourism in Turkey, it should be spread out spatially over the country and reduce its pressure on resource values. Moreover, in sustainable tourism approach, the level of benefits to local community is high, and sustainable tourism, with its potential to create socio-economic development, can be used as an effective tool for reducing the both inter-regional and intra-regional development disparities.

As a result, at the initial phase the sustainable tourism framework in Turkey has continued to expand although it is restricted to suggesting alternative tourism types to mass tourism or implementing some ecological practices at business level. However, sustainable tourism has not been internalized in Turkey yet and it has not been extended to all types of tourism sector. In this context, there is still need for encouraging the implementation of sustainable tourism and tourism planning and disseminating the best practice from the destination level to the regional scale.

\section{Referanslar/References}

Bardakoğlu, Ö. (2014). Sürdürülebilir Turizm ve Planlama. Metin Kozak (Ed.), Sürdürülebilir Turizm KavramlarUygulamalar içinde (195-212). Ankara: Detay Yayıncılık.

Boyacıoğu, E. Z. (2015). Bölgesel Kalkınmada Turizmin Etkisi. Derman Küçükaltan vd. (Ed.), Değisşik Perspektifleriyle Turizm Politikası ve Planlaması içinde (195-212), Ankara: Detay Yayıncılık.

Connell, J., Page, S., Bentley, T. A. (2009). Towards Sustainable Tourism Planning in New Zealand: Monitoring Local Government Planning Under the Resource Management Act. Tourism Management, 30 (6), 867-877. doi: 10.1016/j.tourman.2008.12.001.

Çalık, M., Sözbilir, M. (2014). İçerik Analizinin Parametreleri. Eğitim ve Bilim, 39 (174). 33-38. doi: 10.15390/EB.2014.3412.

Çetinel, F., Yolal, M. (2009). Public Policy and Sustainable Tourism in Turkey. TOURISMOS: An International Multidisciplinary Journal of Tourism, $4 \quad$ (3), $35-50 . \quad$ https://mpra.ub.unimuenchen.de/25418/1/MPRA_paper_25418.pdf adresinden alınd1.

Çevre ve Şehircilik Bakanlığı (2017). Şehircilik Şurası Komisyon Raporları. Ankara.

Dadakoğlu, A. (2016). Sürdürülebilir Turizmin Gelişiminde Çevreye Duyarlı Konaklama Tesisleri ve Türkiye İçin Öneriler. Kalkınma Bakanlığı Uzmanlık Tezi, Ankara.

Devlet Planlama Teşkilatı Müsteşarlığı (2007). Dokuzuncu Kalkınma Planı Turizm Özel İhtisas Komisyonu Raporu. Ankara.

Dinçer, Z. M., Çetin, G. (2015). Kalkınma Planlarında Turizm. Derman Küçükaltan vd. (Ed.), Değişik Perspektifleriyle Turizm Politikası ve Planlaması içinde (171-192), Ankara: Detay Yayıncılık.

Eagles, P. F. J., McCool, S. F., Haynes, C. (2002). Sustainable Tourism in Protected Areas: Guidelines for Planning and Management. Best Practice Protected Area Guidelines, IUCN Series No: 8., Switzerland.

Gürbüz, S., Şahin, F. (2014). Sosyal Bilimlerde Araştırma Yöntemleri. Ankara: Seçkin Yayıncılık.

Hatipoglu, B., Alvarez, M. D., Ertuna, B. (2016). Barriers to Stakeholder Involvement in the Planning of Sustainable Tourism: the Case of the Thrace Region in Turkey. Journal of Cleaner Production, 111, 306-317. doi: 10.1016/j.jclepro.2014.11.059.

İncekara, A. (2001) Anadolu'da Yeni Turizm Olanaklarl ve Bölgesel Kalkınmadaki Yeri. İstanbul Ticaret Odası, Yayın no. 2001-28, İstanbul.

Jacobus, A. (2006). Sustainable Development - Historical Roots of the Concept. Environmental Sciences, 3 (2), 83-96. doi: $10.1080 / 15693430600688831$.

Kalkınma Bakanlığı (2012). Türkiye'de Sürdürülebilir Kalkınma Raporu: Geleceği Sahiplenmek. Ankara.

Kalkınma Bakanlığı (2013). Onuncu Kalkınma Planı (2014-2018). Ankara.

Kalkınma Bakanlığı (2014a). Bölgesel Gelişme Ulusal Stratejisi (2014-2023), Ankara. 
Kalkınma Bakanlığı (2014b). Onuncu Kalkınma Planı Turizm Özel İhtisas Komisyonu Raporu. Ankara.

Kalkınma Bakanlığı (2017). Sürdürülebilir Kalkınma Hedefleri Kapsamında Türkiye’nin Mevcut Durum Analizi Projesi Taslak Raporu. Ankara (http://www.surdurulebilirkalkinma.gov.tr/wpcontent/uploads/2017/10/SDG_AnaRapor_05102017_Final-web-i\%C3\%A7in.pdf, 06.12.2017).

Kalkınma Bakanlığı (2018a). Ekonomik ve Sosyal Göstergeler (1950-2014). Ankara (http://www.kalkinma.gov.tr/Pages/EkonomikSosyalGostergeler.aspx, 10.12.2017).

Kalkınma Bakanlığı (2018b). 2014-2023 Bölge Planları. Ankara (http://bolgesel.kalkinma.gov.tr/bolge-planlari/210.12.2017).

Kalkınma Bakanlığı (2018c). On Birinci Kalkınma Planı (2019 - 2023) Özel İhtisas Komisyonları ve Çalışma Grupları El Kitabı. Ankara.

Kalkınma Bankası (1998). Rakamlarla Dünyada ve Türkiye'de Turizm Sektörü (Türkiye Iç̧in Turizm Talep Tahmini). Araştırma Müdürlüğü, Yayın No. SA/98-2-17, Ankara.

Kervankıran, İ. (2015). Contribution of the Five-Year Development Plans to Tourism in Turkey. Turkish Studies, 10 (2), $587-$ 610. doi: 10.7827/TurkishStudies.7819.

Kervankıran, İ., Çuhadar, M. (2016). Türkiye'de Yabancı Turist Dağılımının Mekânsal Kümelenme Analizi. Journal of Recreation and Tourism Research, 3 (3), 53-63. http://pbs.sdu.edu.tr/api/api/yayin/AbstractGetir?yayinid=175591 adresinden alınd1.

Kozak, N., Akoğlan, M., Kozak, M. (1997) Genel Turizm: Illkeler ve Kavramlar. Ankara:Turhan Kitabevi.

Kültür ve Turizm Bakanlığı (2007a). Türkiye Turizm Stratejisi (2023). Ankara.

Kültür ve Turizm Bakanlığı (2007b). Türkiye Turizm Stratejisi (2023) ve Eylem Planı (2007-2013). Ankara.

Kültür ve Turizm Bakanlığı (2018). 3. Turizm Şurası Şura Kitabı. Ankara.

Liu, Z. (2003). Sustainable Tourism Development: A Critique. Journal of Sustainable Tourism, 11(6), 459-475. doi: $10.1080 / 09669580308667216$.

Meadows, D. H., Meadows, D. L., Randers, J., Behrens, W. W. (1972). The Limits to Growth. New York:Universe Books.

Oktayer, N., Susam, N., Çak, M. (2007). Türkiye'de Turizm Ekonomisi. İstanbul Ticaret Odası Yayınları: 2007-69, İstanbul.

Özgüç, N. (2007). Turizm Coğrafyası: Özellikler ve Bölgeler. İstanbul: Çantay Kitabevi.

Ruhanen, L. (2006). Sustainable Tourism Planning: an Analysis of Queensland Local Tourism Destination Planning. Basılmamış Doktora Tezi, The University of Queensland, Australia, (http://espace.library.uq.edu.au/eserv/UQ:158104/n02content-Ruhanen-Hunter-lisa.pdf, 10.12.2017).

Sarı, V. İ., Yener, I. N., İnan, Ö. (2018). Mekânsal Planlama Sistemine İlişkin Değerlendirme Raporu. Kalkınma Bakanlığı, Ankara.

Sarışık, M., Genç, K. (2017). Sürdürülebilir Turizm Konusunda Yapılan Bilimsel Çalışmalar Üzerine Nicel Bir Değerlendirme (2000-2016), 4th International Congress of Tourism \& Management Researches, https://www.researchgate.net/publication/317799006_Surdurulebilir_Turizm_Konusunda_Yapilan_Bilimsel_Calisma lar_Uzerine_Nicel_Bir_Degerlendirme_2000-2016,12.12.2017).

Somuncu, M., Yiğit, T. (2009). Göreme Milli Parkı ve Kapadokya Kayalık Sitleri Dünya Mirası Alanı'ndaki Turizmin Sürdürülebilirlik Perspektifinden Değerlendirilmesi. V. Ulusal Coğrafya Sempozyumu 2008 Bildiriler Kitabı, Ankara, 387-402. http://tucaum.ankara.edu.tr/wp-content/uploads/sites/280/2015/08/semp5_39.pdf adresinden alınd1.

Sonuç, N. (2014). Sürdürülebilir Turizm: Tanımı ve İçeriği. Metin Kozak (Ed.), Sürdürülebilir Turizm KavramlarUygulamalar içinde (14-28), Ankara:Detay Yayıncılık.

Tekeli, İ. (2001). Sürdürülebilirlik Kavramı Üzerinde İrdelemeler. Cevat Geray'a Armağan içinde (729-740), Ankara: Mülkiyeliler Birliği Yayınları.

Tekeli, İ. (2013). Sürdürülebilir Bir Toplum ve Çevre Tasarımı İçin Bir Strateji Seçenekleri Yelpazesi Oluşturmak, İzmir Büyükşehir Belediyesi Akdeniz Akademisi.

Torres-Delgado, A., Palomeque, L. F. (2014). Measuring Sustainable Tourism at the Municipal Level. Annals of Tourism Research, 49,122-137. doi: 10.1016/j.annals.2014.09.003

Tosun, C. (2001). Challenges of Sustainable Tourism Development in the Developing World: The Case of Turkey, Tourism Management, 22 (3), 285-299. doi:10.1016/S0261-5177(00)00060-1.

Tosun, C. (2008) Promoting a Sustainable Tourism: National Study for Turkey, Mediterranean Strategy for Sustainable Development. Plan Bleu:Sophia Antipolis.

Tosun, C., Jenkins, C. L. (1996). Regional Planning Approaches to Tourism Development: The Case of Turkey. Tourism Management, 17 (7), 519-531. doi:10.1016/S0261-5177(96)00069-6.

Tutar, E., Tutar, F. (2004). Turizm, Ekonomi, Türkiye ve OECD. Ankara: Seçkin Yayınları. 
TÜRSAB (2018). Turizmin Ekonomideki Yeri. (https://www.tursab.org.tr/tr/turizm-verileri/istatistikler/turizmin-ekonomidekiyeri/gsmh-icindeki-payi-1963-_79.html_20.06.2018).

TÜSİAD (2012). Sürdürülebilir Turizm. TÜSİAD-T/2012-09/531, İstanbul.

UNEP, UNWTO (2005). Making Tourism More Sustainable: A Guide For Policy Makers. WTO, Madrid.

UNWTO (2013). Sustainable Tourism for Development Guidebook. (http://www2.unwto.org/en/content/sustainable-tourismdevelopment-developing-countries-document-three-interlinking-parts 2 11.11.2017).

UNWTO (2017). Tourism Highlights 2016 Edition. (http://sdt.unwto.org/content/about-us-5, 18.11.2017).

Yamanoğlu, K. B. (2010). Turizm Sektörü Raporu: Turizm Talebinin Vektör Otoregresif Regresyon ve Mevsimsel Otoregresif Hareketli Ortalama Modeli ile Tahmini. Türkiye Kalkınma Bankası A.Ş., Kredi Değerlendirme II Müdürlüğü, Ankara. 